\title{
ASTEC-MAAP Comparison of a 2 Inch Cold Leg LOCA until RPV Failure
}

\author{
J. C. de la Rosa Blul ${ }^{1},{ }^{1}$ S. Brumm, ${ }^{1}$ F. Mascari, ${ }^{2}$ S. J. Lee, ${ }^{3}$ and L. Carenini ${ }^{4}$ \\ ${ }^{1}$ European Commission Joint Research Centre, Netherlands \\ ${ }^{2}$ Italian National Agency for New Technologies, Energy and Sustainable Economic Development, Italy \\ ${ }^{3}$ Fauske \& Associates, LLC, USA \\ ${ }^{4}$ Institute for Radioprotection and Nuclear Safety, France
}

Correspondence should be addressed to J. C. de la Rosa Blul; juan-carlos.de-la-rosa-blul@ec.europa.eu

Received 6 September 2018; Accepted 29 October 2018; Published 2 December 2018

Academic Editor: Enrico Zio

Copyright (C) 2018 J. C. de la Rosa Blul et al. This is an open access article distributed under the Creative Commons Attribution License, which permits unrestricted use, distribution, and reproduction in any medium, provided the original work is properly cited.

A 2 inch, cold-leg loss-of-coolant accident (LOCA) in a 900 MWe generic Western PWR was simulated using ASTEC 2.1.1 and MAAP 5.02. The progression of the accident predicted by the two codes up to the time of vessel failure is compared. It includes the primary system depressurization, accumulator discharge, core heat-up, hydrogen generation, core relocation to lower plenum, and lower head breach. The purpose of the code comparison exercise is to identify modelling differences between the two codes and the user choices affecting the results. The two codes predict similar primary system depressurization behaviour until the accumulation injection, confirming similar break flow and primary system thermal-hydraulic response calculations between the two codes. The choice of the accumulator gas expansion model, either isentropic or isothermal, affects the rate and total amount of coolant injected and thereby determines whether the core is quenched or overheated and attains a noncoolable geometry during reflooding. A sensitivity case was additionally simulated by each code to allow comparisons to be made with either accumulator gas expansion models. The two codes predict similar amount of in-vessel hydrogen generated and core quench status for a given accumulator gas expansion model. ASTEC predicts much larger initial core relocation to lower plenum leading to an earlier vessel failure time. MAAP predicts more gradual core relocation to lower plenum, prolonging the lower plenum debris bed heat-up and time to vessel failure. Beside the effect of the code user in conducting severe accident simulations, some discrepancies are found in the modelling approaches in each code. The biggest differences are found in the in-vessel melt progression and relocation into the lower plenum, which deserve further research to reduce the uncertainties.

\section{Introduction}

After the nuclear events unfolded in Fukushima, the interest in severe accidents in nuclear power plants has increased greatly [1-3], both in severe accident management and in severe accident phenomena research. Because of high level of complexity and interplay between different phenomena, state-of-the-art integrated severe accident codes such as ASTEC [4], MAAP [5], and MELCOR [6] are often used to study and design accident management strategies [7]. These simulation codes, which capture theoretical and experimental knowledge produced in the last four decades, predict progression of a postulated accident leading to fuel melting, core relocation to lower plenum, and vessel failure.
In addition to the input files describing the plant design, the code user has to choose among several models and correlations for individual phenomena in order to address uncertainties. Although there were several severe accident experiment campaigns [8-12] which produced valuable databases [13], there remain substantial uncertainties that need to be reduced further [14]. In particular, there is scarcity of experiments with prototypic reactor components and materials. As a result, significant discrepancies are often observed in key quantities predicted by different codes such as hydrogen generation, coolability of the core during reflooding, vessel failure, and molten corium-concrete interaction. Attempts to identify research priorities needed to advance the severe accident knowledge and code validation are reported in $[15,16]$. 
To address the gap in the experimental database and in modelling and simulation, many multinational efforts were launched to guide research and development efforts. Several research activities in national and international framework were done and in progress in order to reduce the epistemic uncertainty in severe accident phenomena and to prevent or mitigate severe accidents. These efforts include the Code for European Severe Accident Management (CESAM) project developed under the $7^{\text {th }}$ Framework Programme of the European Commission [17], the In-Vessel Melt Retention Severe Accident Management Strategy for Existing and Future NPPs (IVMR) project, which is still in progress under the H2020 Framework Programme of the European Commission [18], and the European Corium Experimental Research Roadmap (SAFEST) [19], which is also funded under the auspices of the H2020 Framework Programme of the European Commission. The OECD/NEA/CSNI has also sponsored several projects such as the BSAF (Benchmark Study of the Accident at Fukushima) [20], Informing Severe Accident Management Guidance and Actions through Analytical Simulation [21], and the State-of-the-Art Report on Molten Corium Concrete Interaction and Ex-Vessel Molten Core Coolability [22]. Under the IAEA framework, it is worth noting the technical meeting on the Status and Evaluation of Severe Accident Simulation Codes for Water Cooled Reactors held in Vienna on 9-12 Oct 2017 [23], whose main outcome will be a TECDOC on the status of severe accident codes and models. In addition, comprehensive, in-depth code-to-code comparison exercises, also called "crosswalk" activities, led by the code developer teams have been performed in order to identify key modelling differences between the codes. Good examples are the MAAP-MELCOR and the ASTEC-MELCOR crosswalks reported in $[24,25]$, respectively. Another recent work addressing the uncertainties in integrated tools attempts to provide insights through Best-Estimate Plus Uncertainty approach [26].

The impact the code user has on the results of thermalhydraulic system codes is documented in [27-29]. The main conclusion of these studies is that, in order to choose right models and model parameters appropriate for the specific accident scenario, the code user should have good understanding of the phenomena and processes involved. On the other hand, the recent OECD report "Benchmark Study of the Accident at the Fukushima Daiichi Nuclear Power Plant" highlights the difference in the code results after the core geometry is lost, attributing the cause to "each code's modelling approaches" [20]. Therefore, different modelling approach after the loss of core geometry seems to be the leading cause of the persistent, nonreducible uncertainties in the code prediction. This conclusion is supported by the MAAPMELCOR crosswalk study [24], where the major differences between the results are attributed to the different modelling approaches after core damage has occurred. The work presented here attempts to confirm this conclusion and to investigate to what extent the discrepancies can be attributed to the different modelling approaches versus user effects through user choices of appropriate models and model parameters.

A small break LOCA without active cooling before RPV failure is ranked among the highest risk-significant sequences in the severe accident domain of PWRs [30]. The goal of the current work is to compare the results predicted by ASTEC and MAAP for a 2 inch, cold-leg LOCA without ECCS before RPV failure. Significant differences between the two codes are identified and the underlying causes for the differences are discussed.

The current work was performed as part of the European Commission Joint Research Centre activities within the Code for European Severe Accident Management (CESAM) project under the auspices of the $7^{\text {th }}$ Framework Programme of the European Commission.

\section{Description of the Plant and Models}

The reference plant used in the analysis is a generic, 900 MWe, 3-loop Western PWR with three passive accumulators connected to each of the three cold legs.

The ASTEC 2.1.1 model of the plant is based on the input deck provided by IRSN during the CESAM project $[31,32]$. Figures 1, 2, and 3 show the containment, primary system, and secondary system model, respectively (regarding Figure 2, the primary system third loop (not shown), follows exactly the same nodalization that loop 2 (the loop without pressurizer)). The core is divided into 6 radial and 24 axial active nodes plus the upper and lower nonactive nodes for supporting structures. The core model includes the structural components such as the core barrel, baffle, support plates, and structural columns.

The MAAP 5.0.2 model of the plant is based on the information gathered in $[31,32]$ and released to the CESAM partners. The MAAP core model was made consistent with the ASTEC model in decay power, fuel characteristics, mass distribution and relative elevations. Both models have similar initial water masses, dimensions, elevations, safety and relief valves, initial thermodynamic conditions and heat sinks in the primary and secondary systems. The safety systems were also implemented in a similar way. They include ECCS, accumulators, and containment spray system set points and flowrates.

The MAAP core model follows ASTEC's in terms of nodalization, elevations, and materials. It features 6 radial and 24 axial nodes for the active fuel region. In addition, 4 nonactive nodes below the active fuel region are to represent the nonfuel extension and lower support plates, and 2 nonactive nodes above the active core region are to represent the nonfuel extension and upper support plates. Figure 4 shows the elevations of the active fuel nodes (in red), upper nonactive fuel nodes (T-1 and T-2), and lower nonactive fuel nodes in the MAAP model (B-1 to B-4). The vessel internals such as the core barrel, baffle, plates, and columns are modelled separately with similar geometry, mass, and material in the two codes.

Both ASTEC and MAAP nodalize the lower head using 8 axial nodes and 5 radial nodes.

In MAAP the primary system nodalization is fixed whereas in ASTEC the user has control over nodalization. The primary system nodalization scheme is compared between ASTEC and MAAP in [31]. It was found that the two models are similar in representing the individual components in 


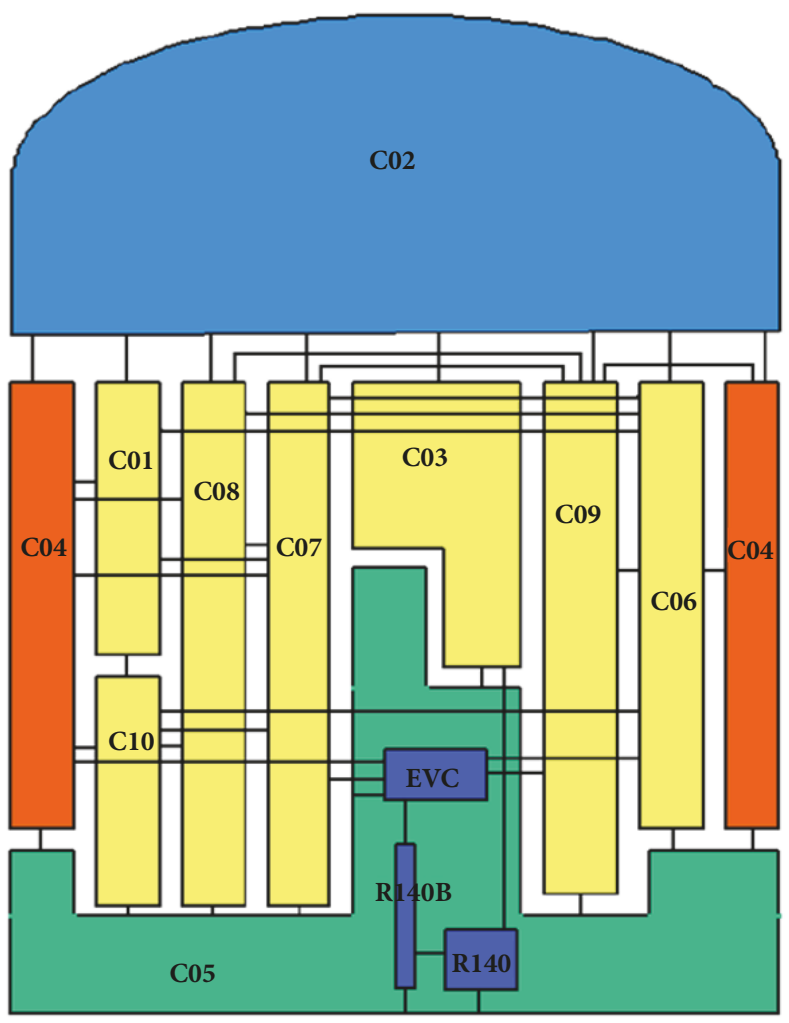

FIGURE 1: ASTEC containment nodalization of the PWR 900 MWe reference reactor [31].

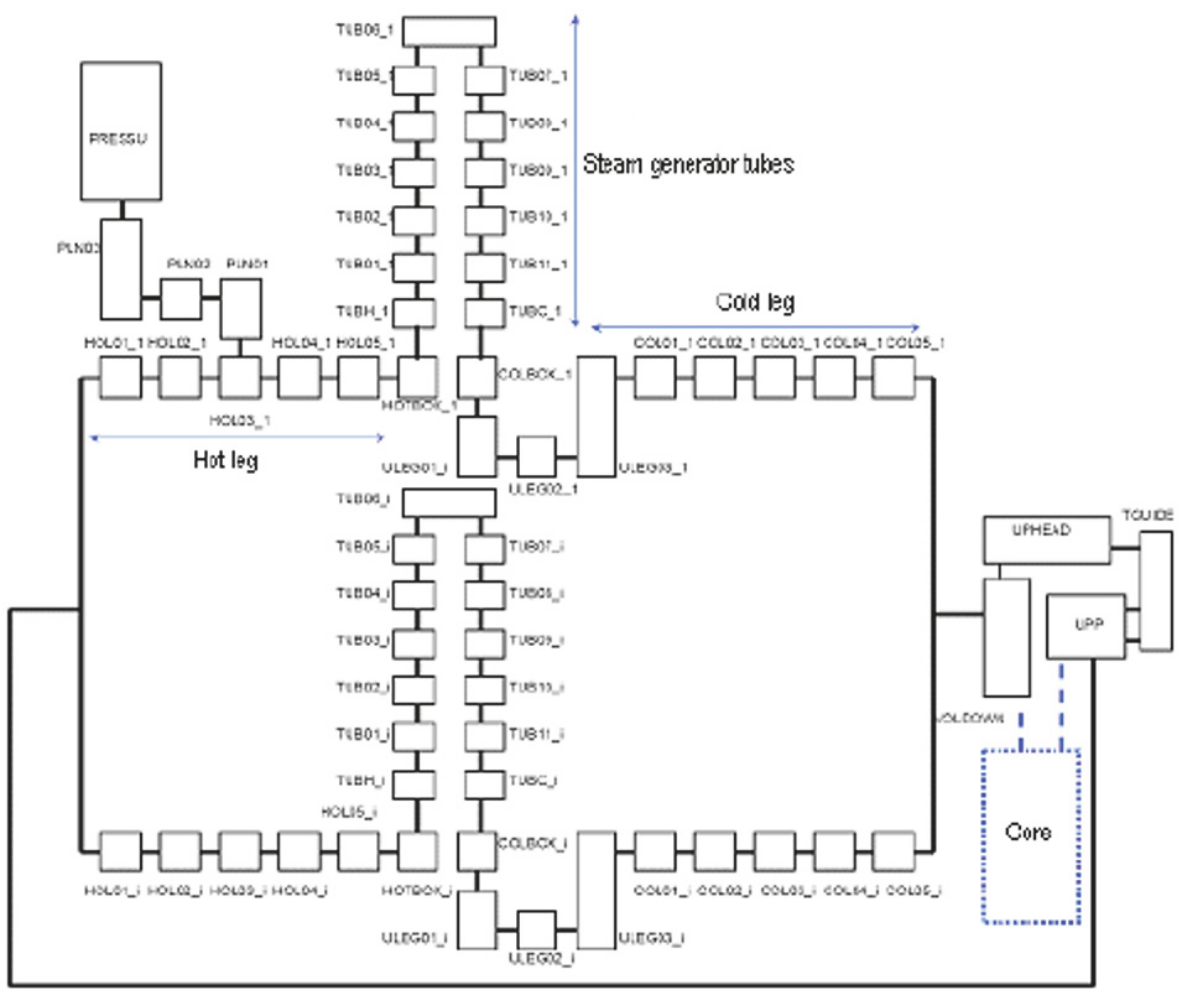

FIGURE 2: ASTEC primary system nodalization [31]. 


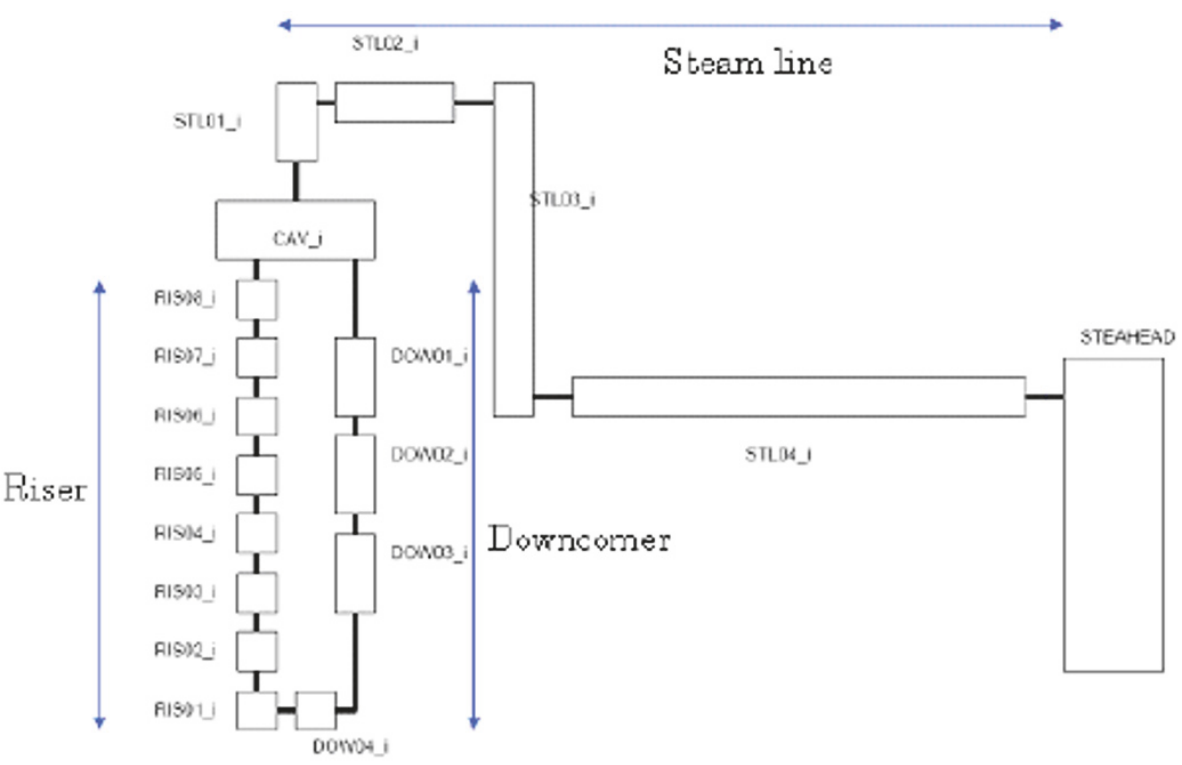

FIGURE 3: ASTEC secondary system nodalization [31].

NODE ELEV. ELEV.

HEIGHT
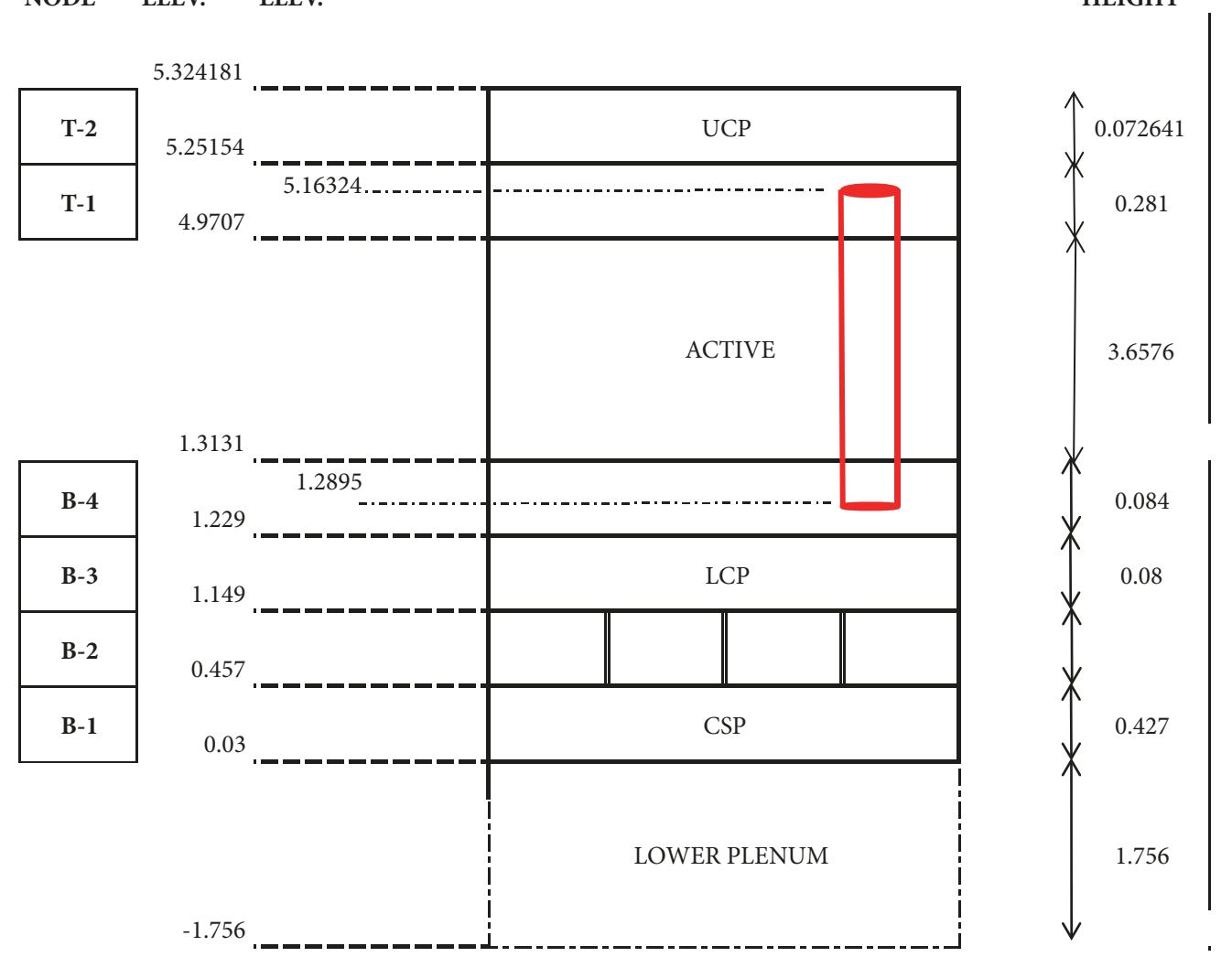

FIgURE 4: Simplified layout of one fuel bundle. 
TABLE 1: Comparison of the steady state operational conditions predicted by ASTEC and MAAP.

\begin{tabular}{lccc}
\hline & VARIABLE & ASTEC 2.1.1 & MAAP 5.0.2 \\
\hline & Cold leg flowrate [kg/s] & 4735.6 & 4735.84 \\
& PZR pressure [bar] & 155.16 & 155.87 \\
Primary System & Inlet Core Temperature [K] & 560.06 & 559.55 \\
& Outlet Core Temperature [K] & 594.50 & 594.64 \\
& PZR level [m] & 6.44 & 6.29 \\
\hline \multirow{2}{*}{ Secondary System } & SG recirculation ratio [-] & 4.15 & 4.15 \\
& SG water level [m] & 12.86 & 12.86 \\
& SG pressure [bar] & 58.02 & 58.02 \\
Containment & SG water mass [kg] & 44385 & 44362 \\
\hline
\end{tabular}

TABLE 2: Key automatic and operator actions.

\begin{tabular}{lc}
\hline EVENT & CONDITION \\
\hline Reactor trip & Pressurizer pressure falls below 131 bar \\
\hline Isolation of accumulators & Primary pressure falls below 15 bar \\
\hline Steam generator regulation to 33\% (narrow range) & $\mathrm{t}=\mathrm{t}($ Safety Injection Actuation) \\
\hline Reactor coolant pump trip & Pressurizer pressure falls below 118 bar \\
\hline Safety injection actuation & Pressurizer pressure falls below 119 bar \\
\hline Containment sprays actuation & Containment pressure rises above 2.4 bar \\
\hline
\end{tabular}

the primary system: hot leg, SG primary and secondary components (water box, $\mathrm{U}$ tubes, etc.), cold leg, intermediate leg (loop seal leg), pressurizer, etc.

The containment compartments, junctions, heat sinks, and reactor cavity configuration in the ASTEC model were implemented in the MAAP model.

In order to check the consistency between the two models, a steady-state case was simulated using the two codes, where the ASTEC steady-state data has been taken from [33]. The results are in good agreement as shown in Table 1.

\section{Preliminary Remarks on the Scenario}

The scenario simulated is a 2 inch break in the cold leg. All active primary system coolant injection is assumed to be unavailable before RPV failure. Table 2 summarizes the key automatic and operator actions.

Since the standard reference SBLOCA experiments were conducted with break sizes ranging between $0.5 \%$ and $5 \%$ [34], the present $6 \%$-equivalent break LOCA is expected to behave between an SBLOCA and MBLOCA in terms of primary system depressurization and accumulator discharge rate. The reactor thermal-hydraulic response to breaks of this size as initiating event has shown large sensitivity to the initial and plant-specific conditions. A small difference in the break size and location, thermal power, cross-over leg relative elevation, or manual actions taken on the secondary side can lead to a different plant evolution, affecting, among others, safety system actuations driving the plant to a safe state $[35,36]$. Nevertheless, responses to relatively small break LOCAs share the following characteristics until the onset of core damage [34]:
(1) Initially, since the break is not big enough to remove all the steam generated by decay heat, the primary system pressure stays slightly above the secondary side pressure so that the secondary side can act as a heat sink and remove the excess heat.

(2) If HPSI is not available and no manual actions are taken on the secondary side to depressurize the primary system, the core will eventually become uncovered and heat up before the steaming rate decreases and thereby depressurize the primary system enough to trigger LPSI.

(3) Once the RCPs are stopped and HPSI is not available, the primary system temperature will rise temporarily as a consequence of the loop seal in the cross-over leg; the primary pressure will also rise correspondingly.

(4) In the absence of a high pressure injection to the vessel, the steaming rate in the core will eventually start to fall and the pressure will start to decrease as the core becomes uncovered and the decay heat decreases. Eventually, the primary system pressure will decrease below the secondary side. Once the primary system pressure falls below the secondary side, the secondary side can no longer act as a heat sink, unless the secondary side is fully depressurized to near the atmospheric pressure.

(5) Provided no manual action is taken to depressurize the secondary side, the accumulators will start injecting water slightly before or after the fuel experiences temperature excursion, depending on the break size. If core damage has already occurred, it may have lost its original coolable geometry and the accumulator injection may not be able to cool the core. On the other hand, if the core retains its original geometry, the core can be cooled by the injection. 
TABle 3: Phenomenological windows identified and dominant driving phenomena investigated.

\begin{tabular}{|c|c|c|}
\hline Phase no. & Phase name & $\begin{array}{c}\text { Phenomena considered as a Figure of Merit for code } \\
\text { comparison }\end{array}$ \\
\hline 1 & RCS depressurization & $\begin{array}{c}\text { Break flow } \\
\text { Single and two phase natural circulation } \\
\text { Heat transfer in SG } \\
\text { Loop seal formation and clearing } \\
\text { Steam voiding in RCS } \\
\text { Phase separation in RCS } \\
\text { Core uncovery } \\
\text { Core heat-up } \\
\text { Cladding oxidation and hydrogen generation } \\
\text { Core damage }\end{array}$ \\
\hline 2 & Accumulator discharge & $\begin{array}{l}\text { Accumulator discharge rate and duration } \\
\text { Core reflooding and quenching }\end{array}$ \\
\hline 3 & $\begin{array}{l}\text { Core heat-up and } \\
\text { relocation to lower plenum }\end{array}$ & $\begin{array}{c}\text { Core heat-up } \\
\text { Cladding oxidation and hydrogen generation } \\
\text { Molten pool formation in the core and coolability } \\
\text { Core relocation to lower plenum }\end{array}$ \\
\hline 4 & Debris bed in lower plenum & $\begin{array}{l}\text { Debris bed behaviour in lower plenum } \\
\text { RPV lower head failure }\end{array}$ \\
\hline
\end{tabular}

TABLE 4: Timing of key events in the SBLOCA predicted by ASTEC and MAAP.

\begin{tabular}{lcccc}
\hline & ASTEC_REF [s] & MAAP_REF [s] & ASTEC_SEN [s] & MAAP_SEN [s] \\
\hline 2-inch cold leg SBLOCA & 0.0 & 0.0 & 0.0 & 0.0 \\
\hline Reactor trip & 35 & 42 & 35 & 42 \\
\hline AFW ON & 41 & 42 & 41 & 42 \\
\hline MFW OFF & 55 & 42 & 55 & 65 \\
\hline SG water level at 33\% narrow range & 55 & 66 & 3524 & 3423 \\
\hline CET $=\mathbf{6 4 9}^{\circ} \mathbf{C}^{\mathbf{l}}$ & 3524 & 3423 & 3824 & 3824 \\
\hline Accumulators ON & 3824 & 4029 & 3894 \\
\hline First cladding rupture & 3884 & 3473 & 14274 \\
\hline Accumulators OFF & 8774 & 14652 & 20744 \\
\hline First significant slumping & 15774 & 22671 & 24792 \\
\hline RPV failure & 16864 & 32361 & 8774 \\
\hline
\end{tabular}

\footnotetext{
${ }^{1}$ There exist many different core damage surrogates for PWRs and BWRs. In this work, a core exit thermocouples temperature of 649 Celsius has been selected,
} among others, as it always precedes oxidation transition and it is not overly conservative. For a detailed discussion on this topic, cf. [41].

Once the accumulators are depleted or become disabled, the core will start to heat up again and will eventually melt. At this stage, the accident is entering into the severe accident domain, still characterised by open issues and uncertainties on key phenomena such as core melt progression, hydrogen generation, core relocation to lower plenum, lower plenum debris bed behaviour, and vessel failure.

\section{Introduction to the Analysis of the Scenario}

To facilitate code comparison, the accident progression is divided into four phases as shown in Table $3[13,37]$. The purpose of this study is to investigate code difference by focusing on the key driving phenomena and underlying models in each phase, not to perform an analytical decomposition of all phenomena characterising each phase. A detailed study about all the thermal-hydraulic phenomena in this kind of transient can be found in [38-40]. As for the in-vessel core degradation phenomena, more detailed information about all the core degradation phenomena characterizing this kind of transient can be found in [10].

Each accident progression phase will be analysed in detail, identifying the key driving phenomena. Then, conclusions will be drawn from the following three perspectives:

(1) Code capabilities to simulate the key driving phenomena

(2) Expected trends and values in the key driving phenomena

(3) Significant differences between the two codes

Table 4 summarizes the timing of key events predicted by each code whereas Table 5 shows the key results from the two reference and two sensitivity cases: In addition to 
TABLE 5: Key results in the SBLOCA predicted by ASTEC and MAAP.

\begin{tabular}{|c|c|c|c|c|}
\hline Event & ASTEC_REF & MAAP_REF & ASTEC_SEN & MAAP_SEN \\
\hline $\begin{array}{l}\text { Integrated liquid break mass at } 200 \\
\text { seconds }\end{array}$ & $26600 \mathrm{~kg}$ & $21900 \mathrm{~kg}$ & $26600 \mathrm{~kg}$ & $21900 \mathrm{~kg}$ \\
\hline $\begin{array}{l}\text { Integrated liquid break mass at le } 4 \\
\text { seconds }\end{array}$ & $143395 \mathrm{~kg}$ & $120830 \mathrm{~kg}$ & $136593 \mathrm{~kg}$ & $120830 \mathrm{~kg}$ \\
\hline $\begin{array}{l}\text { Integrated gas break mass at 1e4 } \\
\text { seconds }\end{array}$ & $68800 \mathrm{~kg}$ & $71924 \mathrm{~kg}$ & $80188 \mathrm{~kg}$ & $66775 \mathrm{~kg}$ \\
\hline Primary pressure at 1500 seconds & $7.3 \mathrm{e} 6 \mathrm{~Pa}$ & $7.2 \mathrm{e} 6 \mathrm{~Pa}$ & $7.3 \mathrm{e} 6 \mathrm{~Pa}$ & $7.2 \mathrm{e} 6 \mathrm{~Pa}$ \\
\hline Primary pressure at le 4 seconds & $1.0 \mathrm{e} 6 \mathrm{~Pa}$ & $2.2 \mathrm{e} 6 \mathrm{~Pa}$ & $1.9 \mathrm{e} 6 \mathrm{~Pa}$ & 1.1e6 Pa \\
\hline Accumulator discharged mass & 44.16 tons & 66.94 tons & 68.26 tons & 44.16 tons \\
\hline In-vessel hydrogen generation & $528 \mathrm{~kg}$ & $605 \mathrm{~kg}$ & $586 \mathrm{~kg}$ & $502 \mathrm{~kg}$ \\
\hline Total relocated mass & 167 tons & 127 tons & 147 tons & 127 tons \\
\hline Highest slumping rate & $15100 \mathrm{~kg} / \mathrm{s}$ & $788 \mathrm{~kg} / \mathrm{s}$ & $13100 \mathrm{~kg} / \mathrm{s}$ & $607 \mathrm{~kg} / \mathrm{s}$ \\
\hline Maximum corium pool temperatures & $2760 \mathrm{~K}$ & $2850 \mathrm{~K}$ & $2665 \mathrm{~K}$ & $2850 \mathrm{~K}$ \\
\hline Lower head wall location & $0.4 \mathrm{~m}$ below cylinder & $0.55 \mathrm{~m}$ below cylinder & $0.55 \mathrm{~m}$ below cylinder & $0.55 \mathrm{~m}$ below \\
\hline Type of RPV failure & $\begin{array}{l}\text { Creep rupture by } \\
\text { focusing effect }\end{array}$ & Creep rupture & $\begin{array}{c}\text { Creep rupture by focusing } \\
\text { effect }\end{array}$ & Creep rupture \\
\hline
\end{tabular}

TABLE 6: Computational times and time steps in the analysed cases.

\begin{tabular}{|c|c|c|c|c|}
\hline & ASTEC_REF & MAAP_REF & ASTEC_SEN & MAAP_SEN \\
\hline Computational Time [hh:mm] & 11:31 & $00: 36$ & $12: 18$ & $00: 25$ \\
\hline Time Step [s] & $0.1-10$ & 0.099 & $0.1-10$ & 0.099 \\
\hline
\end{tabular}

the two reference cases (indicated by the suffix $R E F$ ), two additional sensitivity cases were analysed, one for each code (indicated by the suffix SEN). For ASTEC, the sensitivity case was run with the isothermal accumulator expansion similar to the reference isothermal-like MAAP case (as it will be demonstrated later on). For MAAP, the sensitivity case implements the same accumulator injection flowrate predicted by the reference ASTEC isentropic accumulator expansion case. Therefore, comparisons should be made between ASTEC_REF and MAAP_SEN for the isentropic expansion and between ASTEC_SEN and MAAP_REF for the isothermal expansion of the accumulators.

Table 6 shows the elapsed computing times and numerical time steps used in the four analysed cases by the two codes.

\section{First Phase: Primary System Depressurization}

5.1. Phenomenology Analysis. As shown in Figure 5, initially, the primary system depressurizes rapidly as it loses water mass through the break until flashing starts at around 90 seconds.

After the onset of flashing, the primary pressure stabilizes at a pressure slightly above the secondary side since the decay energy generated in the core cannot be removed fully by the steam flow through the break and the excess heat is removed by the secondary side. The excess heat is transferred to the secondary side by the two-phase natural circulation in the primary loop.
As voiding in the primary loop increases, the natural circulation stops due to the formation of loop seals. The primary pressure increases temporarily as the heat removal by the secondary side is lost and steaming in the core increases to compensate for losing the secondary side cooling. At the same time, the primary loop voiding and loss of natural circulation lead to phase separation, and single phase steam exits the break, resulting in a higher volumetric break flowrate. At around 55 seconds, the operator manually lowers the SG water level to $33 \%$ of the narrow range. Coincidently, the formation of loop seals causes temporary increase in the primary pressure. At around 2,800 seconds, one loop seal is cleared. From here on, the break flow can remove all the steam generated in the core.

As the primary coolant boil off continues, eventually the coolant level falls below the TAF and core becomes uncovered. The uncovered part of the core starts to heat up and eventually reaches the triggered temperature when rapid cladding oxidation occurs. At the same time, the steaming rate decreases as the covered fuel area decreases and the primary pressure starts to fall. Eventually the pressure falls below the accumulator set-point of $4.28 \mathrm{e} 6 \mathrm{~Pa}$ at around 3800 seconds and the in-vessel passive injection starts.

Because the core uncovery and subsequent core heat up coincide with the primary system depressurization and accumulator injection, these two phenomena (i.e., damaged core and accumulator injection) are closely coupled and the interaction between the two phenomena plays an important role in determining the progression of the severe accident. 


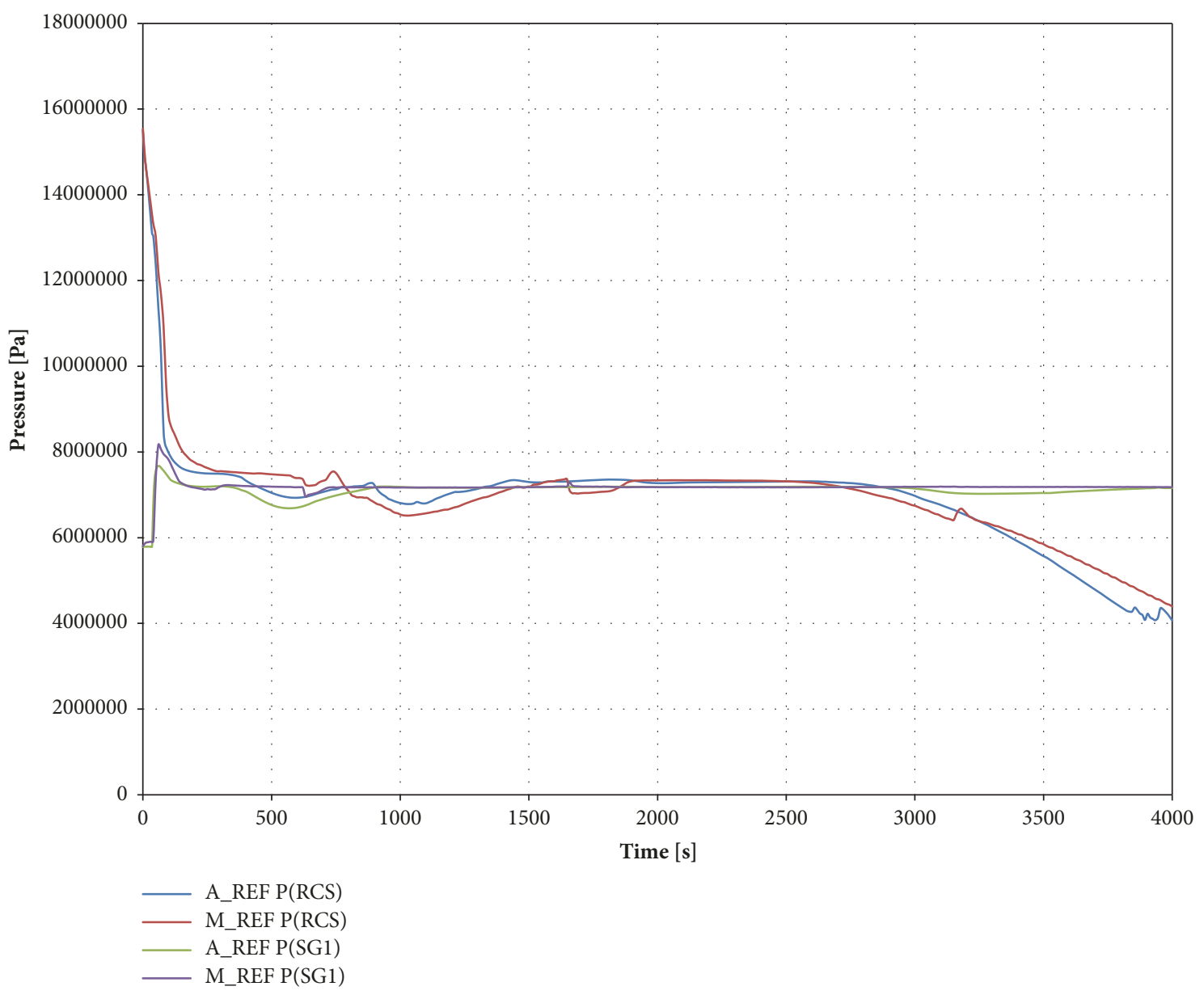

Figure 5: Primary and Secondary (SG1) Pressure Evolutions, $1^{\text {st }}$ Phase (all the figures will follow the same pattern codification: continuous line for the reference case (REF) and dotted line for the sensitivity case (SEN); blue colour for ASTEC (A) and red for MAAP (M)).

\subsection{Conclusions on the $1^{\text {st }}$ Phase}

5.2.1. Code Capabilities. Both codes incorporate suitable models and nodalization scheme to simulate and capture all relevant phenomena to predict consistent break flowrates, primary pressure response, natural circulation in the primary loop, formation of loop seal, phase separation in the primary loop, heat transfer to the secondary side, coolant boil off, and core uncover during the first phase of the accident.

5.2.2. Discussion on the Expected Trends and Values. The two codes predict similar pressure transient and timing before and after the onset of flashing (see Figure 5), including the primary pressure stabilization at a pressure slightly above the secondary side. Both codes predict similar results for the key quantities such as pressures, temperatures, and coolant inventory.

Based on the fact that the primary pressure drops below the secondary pressure relatively quickly, a 2 inch break LOCA will probably be located at the high end of the SBLOCA break range; i.e., it behaves similar to a MBLOCA as discussed above.
5.2.3. Discussion on the Significant Discrepancies between the Codes. As shown in Figure 5, no significant differences are found between the two codes, neither in magnitude (i.e., pressure) nor in width (i.e., timing of the key events). This phase ends at around 4000 seconds.

\section{Second Phase: Accumulators Discharge}

6.1. Phenomenology Analysis. Several studies stress the importance of passive safety injections on preventing core damage (see, e.g., $[42,43])$. The accumulators are designed as a Level 3 engineered safety feature, not as a Level 4 DiD barrier or mitigation system [44]. Nevertheless, since they provide core cooling at a crucial point during an accident, albeit limited in duration and flowrate, they can play an important role in driving the severe accident evolution at least temporary, as demonstrated in the current study.

Consistent with the general understanding of the SBLOCA with no available HPSI and no manual depressurization through the secondary side, the accumulator discharge starts only after the core has uncovered and has been through substantial heat-up. When core reflooding 
starts at the beginning of core damage, before core relocation to the lower plenum has occurred, the accumulator injection flowrate and the primary pressure have positive feedback: the higher the accumulator injection flowrate is, the more effective the core is cooled, causing less cladding oxidation and core steaming rate. Consequently the primary pressure will decrease. The lower the primary pressure, the higher the accumulator injection flowrate in a positive feedback process. On the other hand, the lower the accumulator injection flowrate, the less effective the core is cooled, causing more cladding oxidation and core steaming rate. Consequently the primary pressure will increase. The higher the primary pressure, the lower the accumulator injection flowrate.

Since the accumulator water injected into the cold leg causes an increase in the core inlet flowrate, the boiling front in the core will rise and quench the uncovered core, increasing the steaming rate and supporting the primary pressure from falling. The behaviour of the primary pressure depends on the balance between break flowrate, steaming rate in the core, and condensation rate in SG.

Therefore, aside from the core steaming rate, the break size has a strong influence on the primary pressure evolution for small to intermediate size break LOCAs as it primarily affects the break flowrate. Therefore, the break discharge coefficient [45] and the critical flow model greatly affect the response of the overheated core when the limited-degradedcore is reflooded by the accumulator injection.

In addition, the accumulator injection flowrate and duration depend on the thermodynamic expansion model of the gas in the accumulators, which can fall under the user effect.

Based on the results, the accumulator injection delays core damage but increases the cumulative hydrogen generated in the core, probably by providing additional source of steam to react with cladding. Depending on the accumulator injection flowrate and duration, coolability of damaged core, hydrogen generation, and core melt progression model, the core heat-up and degradation evolve differently. This phase ends up when the primary pressure falls below 15 bar and the accumulators are isolated.

\subsection{Conclusions on the $2^{\text {nd }}$ Phase}

6.2.1. Code Capabilities. Although the accumulator discharge rate and duration have been identified as the main driver for accident progression, the fact that core uncovery and overheating precede accumulator injection makes the coupling between the core damage and the accumulator injection become an early degraded core reflooding phenomenon.

Overall, for a given accumulator gas expansion model, both codes predict similar accumulator injection flowrate and duration, in-vessel FCI, hydrogen generation, core reflooding, core quenching, and delayed core degradation.

6.2.2. Discussion on the Expected Trends and Values. For a given accumulator gas expansion model, both codes predict the expected trends in the primary pressure, temperature, and water inventory. The accumulator discharge rate and duration predicted by the two codes are discussed in detail in the next section.

6.2.3. Discussion on the Significant Discrepancies between the Codes. The accumulator injection flow is driven by the pressure difference between the accumulator and the primary system. The accumulator injection flowrate and duration depend on the thermodynamic expansion of the gas stored in the accumulator [46]. In ASTEC, the user can select the polytropic expansion coefficient which best describes the gas expansion process. In the current study, the polytropic coefficient of 1.4, corresponding to an isentropic expansion, was used for the reference case. In MAAP, the accumulator is modelled using a generic control volume. Hence, while ASTEC allows the user to select the polytropic constant, there is no such option in MAAP 5.02 (MAAP 5.04 is provided with this option). A MAAP sensitivity case was additionally run by imposing the same isentropic-type accumulator injection flowrate as calculated in the ASTEC reference case (called MAAP_SEN).

For the given initial and final pressures, an isothermal expansion of the gas stored in the accumulators results in 35\% higher final volume compared to an isentropic expansion as shown in

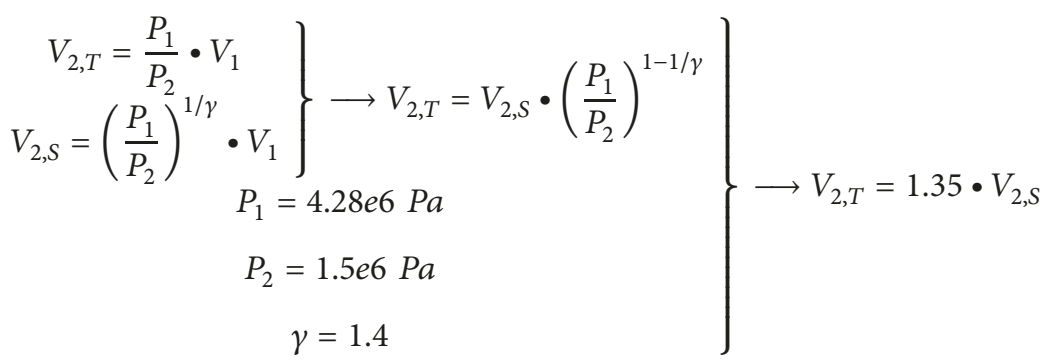

According to the code results, ASTEC predicts a final gas volume of $27.935 \mathrm{~m}^{3}$ whereas MAAP predicts $35.53 \mathrm{~m}^{3}$. The theoretical isothermal expansion would have resulted in the final volume of $37.71 \mathrm{~m}^{3}$, close to the MAAP prediction.
Therefore, MAAP generic control volume of the accumulator behaves very close in the current reference case to an isothermal expansion of gas. For the three accumulators, MAAP predicts a total discharged volume of $22.787 \mathrm{~m}^{3}$, i.e., 


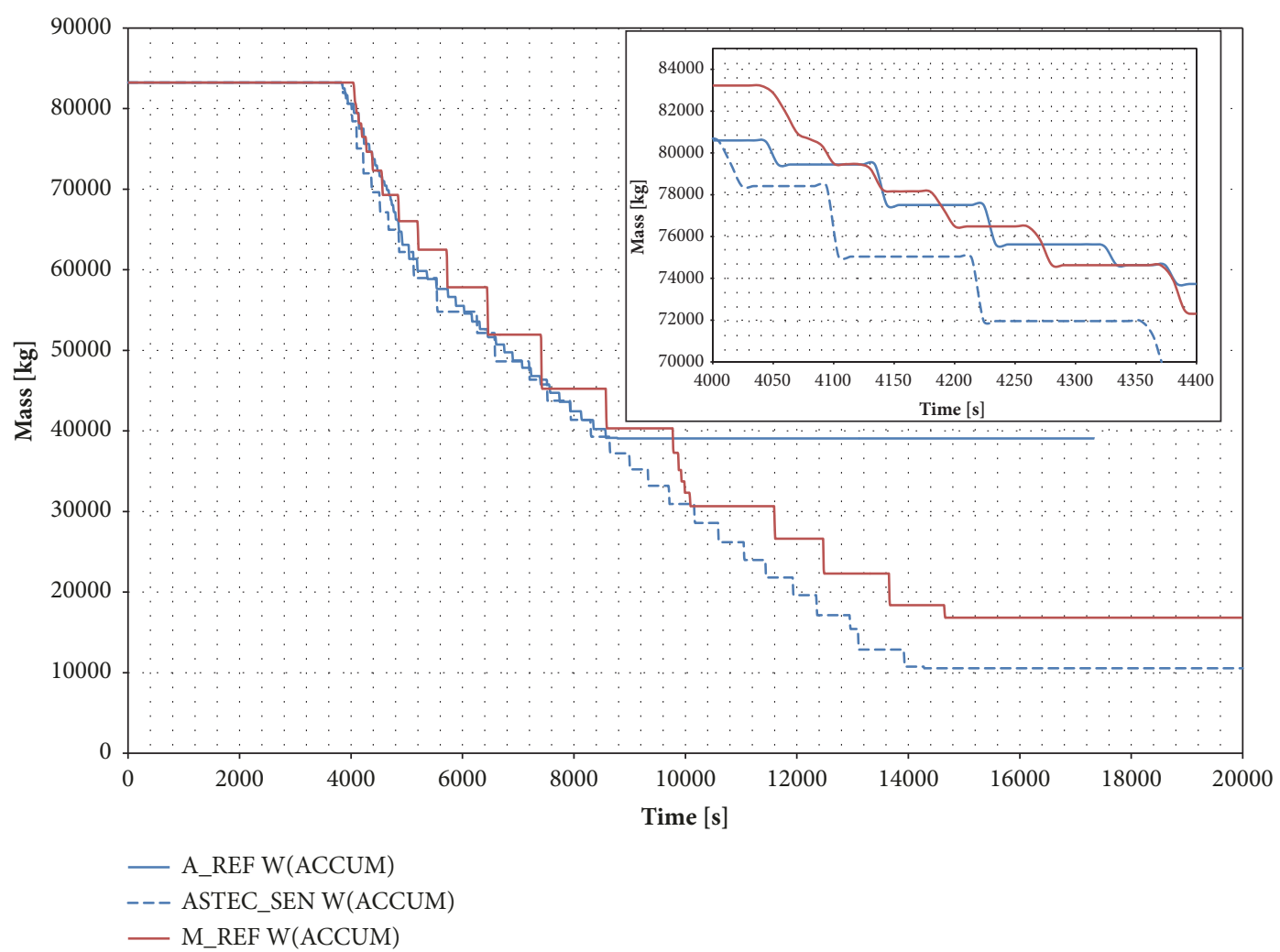

FIgURE 6: Total accumulator mass inventory evolution (zooming between 4000 and 4400 seconds).

about 50\% higher than ASTEC, resulting in a significantly prolonged injection.

Figure 6 shows the remaining mass of water in the accumulators. Figure 7 shows the RCS pressure evolution in the two reference cases and the two sensitivity cases. Figure 8 shows the discharged flowrate by a single accumulator. Figure 9 shows the cumulative mass of hydrogen generated inside the vessel. Figures 10 and 11 show the core exit thermocouple and peak cladding temperature in the fuel, respectively.

In MAAP, the accumulator gas expansion matches very well with an isothermal type even though not fully because the work exerted by the expanding gas to the liquid is not calculated by MAAP. Also, in MAAP the accumulator injection flowrate calculation does not consider the increase in the primary system pressure due to the increased steaming rate in the core. This causes injection flowrate overshooting as shown in Figures 6 and 8. It was found that limiting the time step size based on the maximum fractional change in the accumulator mass to $0.01 \%$ does eliminate the overshooting. Similar but less severe overshooting is observed in the ASTEC results as shown in Figures 6 and 8. Similar observation is reported in several published works including [47]. This phenomenon occurs when partially uncovered and overheated core is quenched from below by core inlet flow.

The accumulator gas expansion process and the corresponding liquid discharge rate depend on the RCS depressurization rate and core overheating. If the core is partially uncovered and overheated, a rapid steaming occurs when the accumulators inject water into the RCS. This leads to a sudden increase in RCS pressure, which stops the accumulators discharge. As the rapid steaming stops in the core and steam is released through the break, the RCS pressure decreases gradually until it falls below the accumulator pressure. The accumulator injection starts again. For the gradual RCS depressurization and intermittent accumulator discharge in SBLOCAs, isothermal expansion of the accumulator gas would be more appropriate [48]. On the other hand, for a rapid RCS depressurization such as in LBLOCAs, the accumulator gas expansion and liquid discharge will take place during a very short period of time. For this case, an isentropic expansion would be more appropriate. This discussion is not intended to provide guidance in choosing the right gas expansion model but to show how the code user choices can affect the results.

The following further observations can be made in the results:

(1) Both codes predict the rapid depressurization subsiding when the accumulators start to inject water into the RCS. After the accumulators start to inject water, the RCS pressure decreases more gradually. The A_REF run predicts a somewhat faster depressurization rate compared to the other cases. In this run, the core has been damaged and has formed a noncoolable geometry at the time the injection starts at 3824 seconds. Hence some of the overheated or molten core is not accessible to the water so that the steaming rate in the core is smaller than the other cases, resulting in 


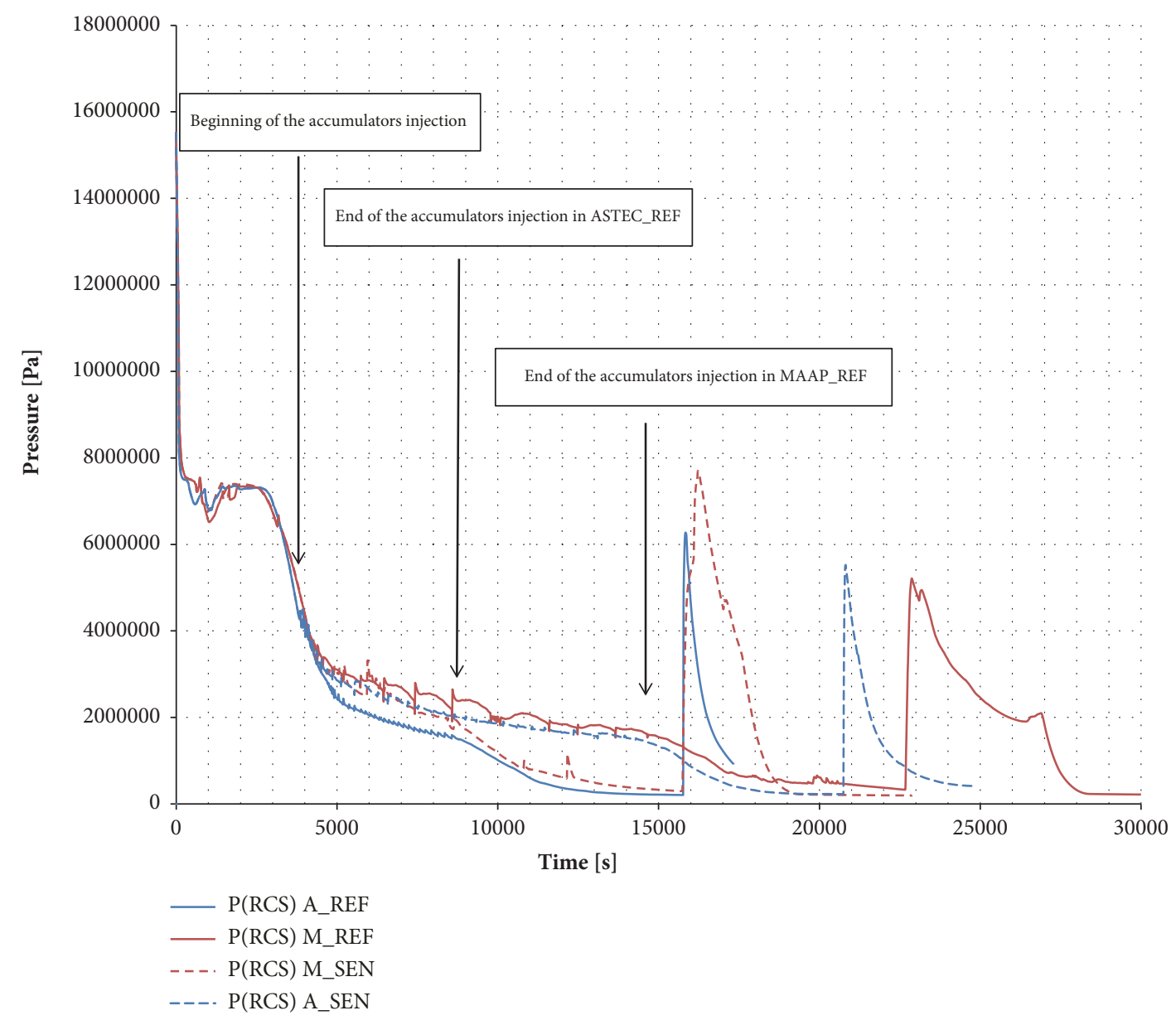

Figure 7: Primary pressure evolution for the reference and sensitivity cases.

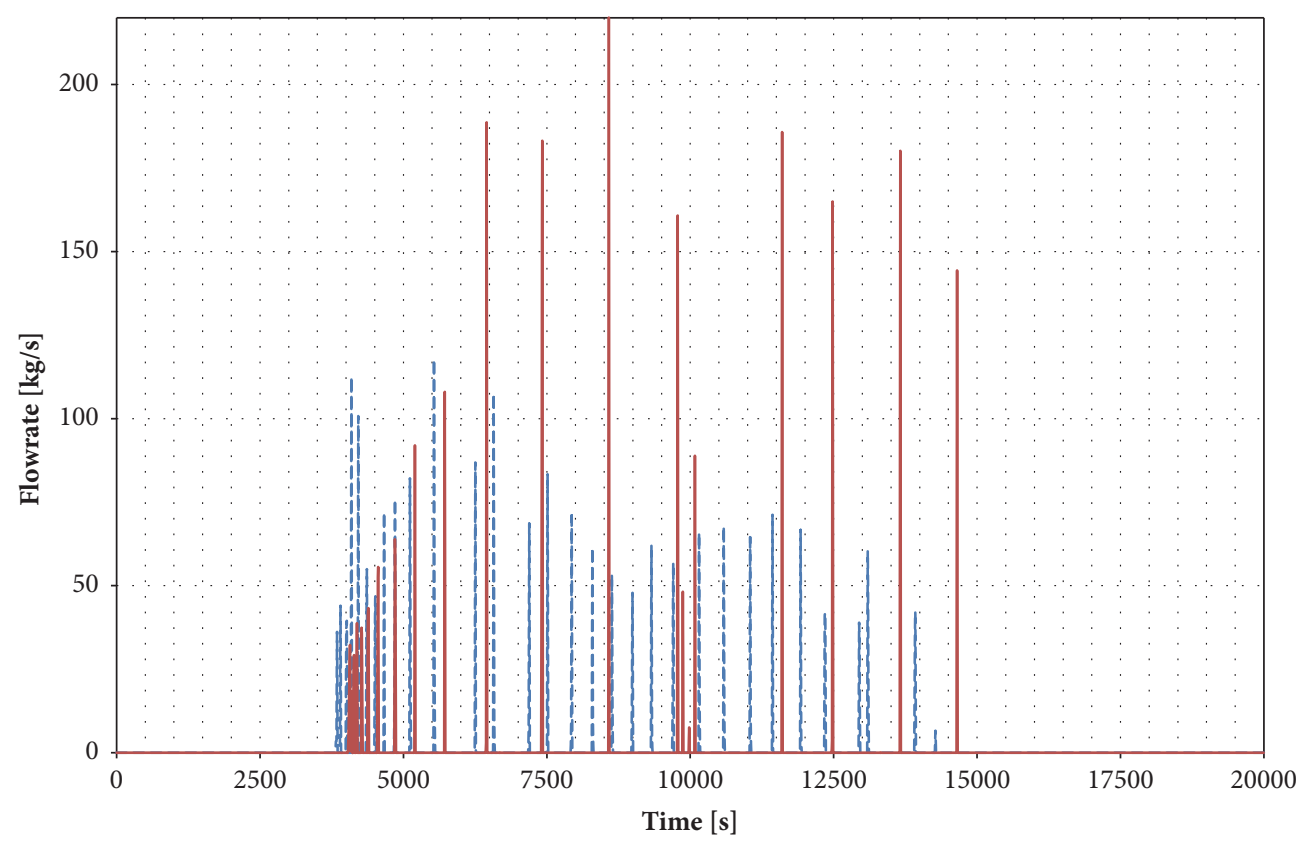

A_SEN W(ACCUM)

— M_REF W(ACCUM)

FIGURE 8: Single accumulator discharged flowrate over time. 


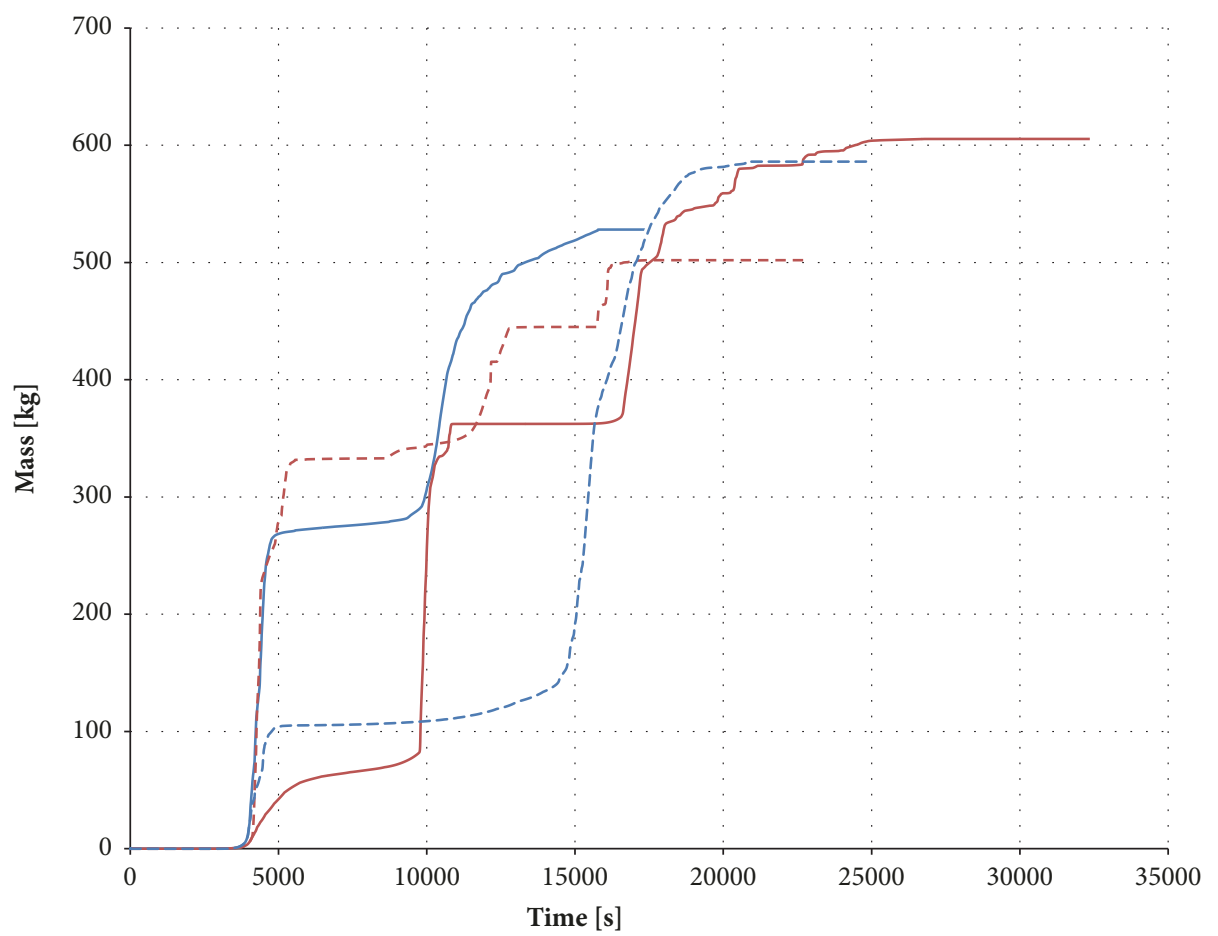

\section{A_REF H2 GENERATION \\ — M REF H2 GENERATION \\ - - - M_SEN H2 GENERATION \\ --- A_SEN H2 GENERATION}

FIGURE 9: In-vessel accumulated hydrogen generation.

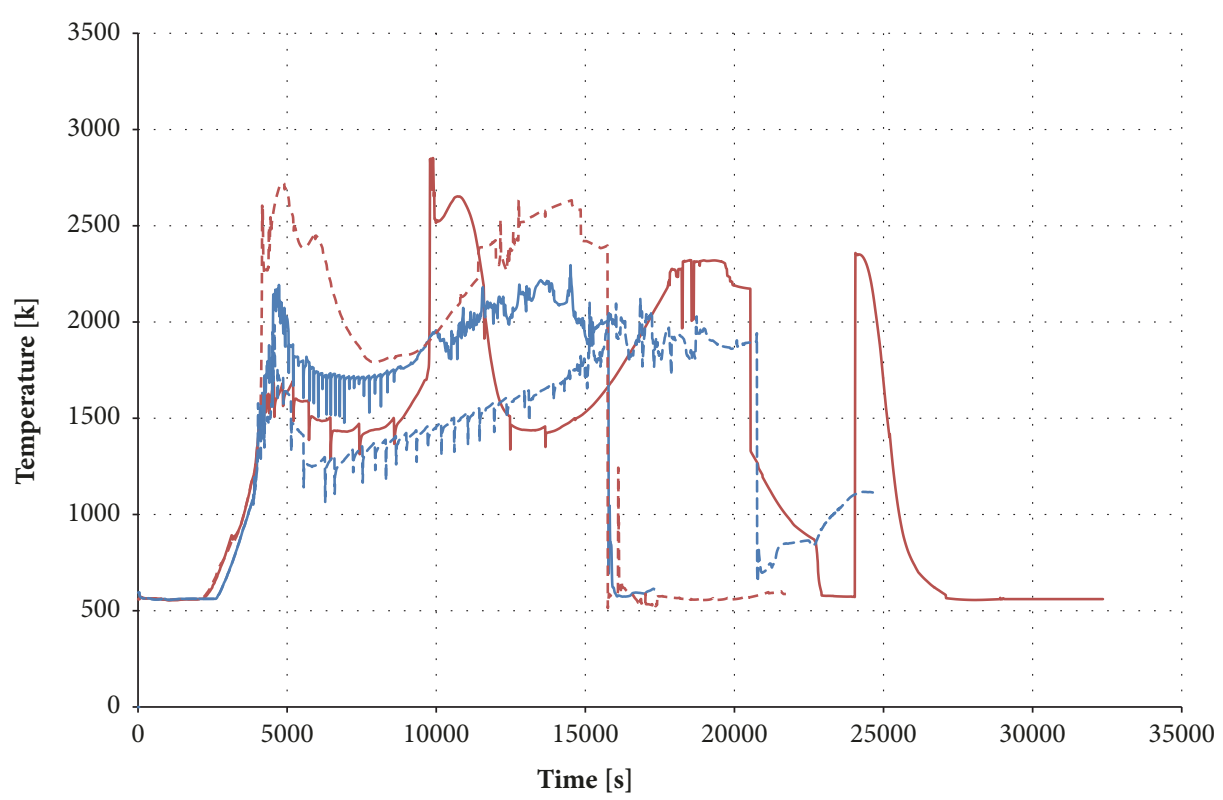

\footnotetext{
- M REF CET

— A_REF CET

- - - M_SEN CET

--- A_SEN CET
}

FIGURE 10: Core exit thermocouple temperatures. 


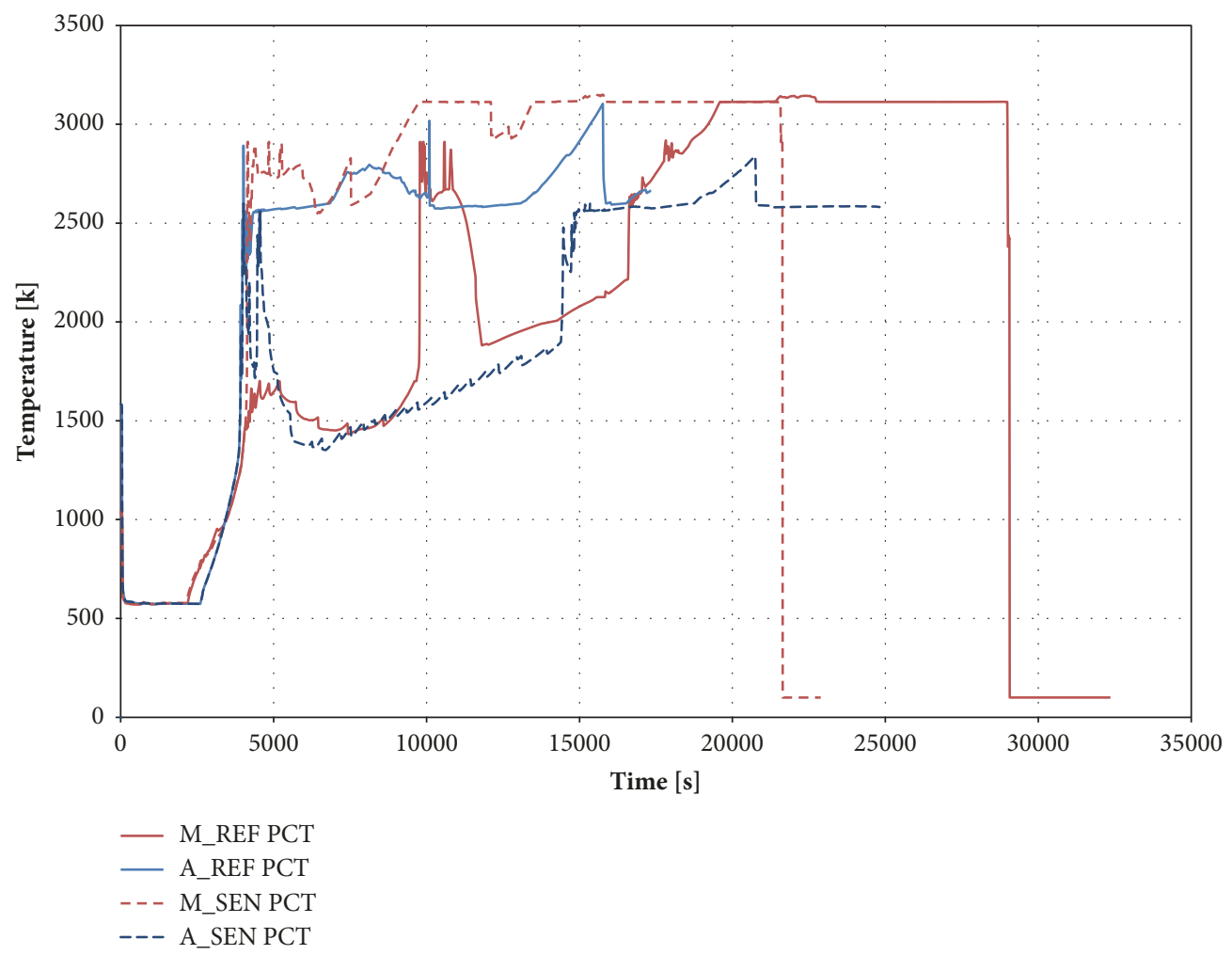

FIGURE 11: Peak clad temperatures.

a faster depressurization rate. With the isentropic expansion model, once the accumulator injection ends at around 9000 seconds the depressurization rate accelerates as shown in cases M_SEN and A_REF in Figure 7.

(2) The two codes predict similar starting time for accumulator injection. This shows that the two codes predict similar break flowrate, natural circulation flowrate, heat transfer rate in SG, and heat transfer rate in the core until the accumulators are triggered.

(3) In all cases, the core is overheated and rapid oxidation of cladding has already started when the accumulators start injecting water as shown in Figure 9. Both ASTEC and MAAP predict that the overheated core will be quenched when the isothermal gas expansion model is used for the accumulator as shown in Figure 10 and clearer in Figure 11 (A_SEN and M_REF). Both ASTEC and MAAP predict that the overheated core will become damaged, and attain a noncoolable geometry when the isentropic gas expansion model is used for the accumulator as shown in Figure 11 (A_REF and M_SEN). Once the core attains a noncoolable geometry, the core interior is not accessible to the coolant and cannot be cooled by the large steam flow. Whether the overheated core is quenched or not depends on the initial flowrate of the accumulator. The initial accumulator flowrate is higher with the isothermal expansion compared to the isentropic expansion (not shown in Figure 6 but was confirmed in the expanded scale plot): between 4000 and 4400 seconds (the duration over which the core can either become quenched or form a molten pool), the total mass injected by the accumulators are $11000 \mathrm{~kg}$ in MAAP_REF (isothermallike case). For MAAP_SEN -just as for ASTEC_REF-, the equivalent injected mass is instead equal to $7000 \mathrm{~kg}$ (hence $36 \%$ less). It appears that the accumulator injection rate, and the resulting steaming rate in the core, is barely sufficient to keep the quenched core cooled; the quenched core in M_REF heats up again and temporarily reaches a noncoolable geometry during the accumulator injection period as shown in Figure 11. Once the accumulator injection is over, the quenched core heats up again.

(4) The rapid cladding oxidation and hydrogen generation occurs just before the accumulator injection starts as shown in Figure 9. The rapid oxidation and hydrogen generation stops when the core is quenched shortly after the accumulator injection starts as shown by the case A_SEN and MAAP_REF in Figure 9. The rapid cladding oxidation and hydrogen generation resume when the accumulator injection ends and the core heats up again after around 15000 seconds. As discussed before, the exception to this conclusion is M_REF, which reheats and temporarily attains noncoolable geometry before the end of accumulator injection.

(5) If the core is not quenched at the start of the accumulator injection, the rapid cladding oxidation and hydrogen generation continues further until all the available fuel cladding surfaces are exhausted as shown by the cases A_REF and M_SEN in Figure 9. More gradual cladding oxidation and hydrogen generation resume when the accumulator injection ends at around 9000 seconds and continued coolant boil-off uncovers fresh fuel cladding. 
As a conclusion, the two codes predict similar fuel cladding oxidation, core overheat, core damage, and thermalhydraulics response during the accumulator injection phase. In particular, quenching of the overheated core by bottom reflooding is realistically simulated by both codes. The melt progression model in MAAP was developed to be able to simulate formation of a molten pool in the core which is not coolable by late injection, as was observed during the TMI-2 accident. Although the current cases rely on the bottom reflooding and steam cooling, the code is able to predict both damaged core configurations; quenched core with the isothermal accumulator expansion model and damaged, uncoolable core with the isentropic accumulator expansion model. ASTEC also predicts the quenched core and damaged, uncoolable core depending on the accumulator gas expansion model. The results from this study also show that the accumulator injection rate is barely able to cool the core as shown in case M_REF, and it can lead to either quenched or uncoolable core. The user should be aware of the uncertainty in the phenomenon and consider both accident progression paths.

\section{Third Phase: Core Heat-Up and Relocation to Lower Plenum}

7.1. Phenomenology Analysis. When the accumulator injection begins, the core heat-up and hydrogen generation have already started. The fuel cladding oxidation and hydrogen generation depend on the fuel temperature, fuel cladding surface area available for reaction, and steam sources. Less damaged core produces more hydrogen. For the same reason, slower core heat-up and degradation processes produce more hydrogen than rapid core heat-up and degradation, typically found at low RCS pressures. In addition, since the cladding oxidation is an exothermal reaction, fuel heatup is accelerated once the cladding reaches a certain elevated temperature. Therefore, the in-vessel injection, if it is not introduced at sufficiently high and sustained flowrates, can accelerate core heat-up and lead to core degradation.

Depending on the accumulator injection rate, the core may either be quenched or attain an uncoolable geometry. Since the accumulator injection rate depends on the RCS pressure, and the RCS pressure in turn depends on the accumulator injection rate and steaming in the core, the accumulator injection rate and the rate at which the RCS pressure is decreasing depends ultimately on the break size. A large break will result in faster RCS pressure falling rate and higher accumulator injection rate, resulting in a quenched core.

The accumulation injection ends when the RCS pressure falls below 15 bar. The fact that the RCS pressure has been supported above the accumulator trip-off pressure means that the core is partially covered and the steaming is still continuing when the accumulator injection ends. Therefore, steaming continues at a lower rate due to the decay heat in the covered section of the core after the end of the injection. If the core is quenched, the uncovered section of the core will heat up again. When the cladding temperature reaches a certain point, oxidation of unreacted cladding will take off, accelerating the core heat-up. The oxidation rate in the uncovered core may be limited by the steaming rate in the covered part of the core. If the core is not quenched, most of the fuel cladding in the uncovered core is either already oxidized or is not accessible to steam because of the changed geometry. Therefore, additional cladding oxidation will be limited to the freshly uncovered core as the coolant boils off. Eventually the core will melt and start to relocate to the lower plenum.

The biggest uncertainty is expected in melt progression in the core and subsequent loss of geometry. The timing and the rate of core relocation to lower plenum will affect the behaviour of the debris bed in the lower plenum and failure of the lower head.

\subsection{Conclusions on the $3^{\text {rd }}$ Phase}

7.2.1. Code Capabilities. Both codes model oxidation of zircalloy cladding by steam at high temperatures. In MAAP the melt progression model combined with rules from subnodal physics creates a periphery of impenetrable, crust-like nodes surrounding the molten debris pool. Molten material cannot flow through a highly packed region, and upward gas flow is diverted around the crust. The outermost and top nodes can develop side and top crusts due to heat losses to the core former and baffle plates, as well as upward to the gas and upper plenum structures. A failure criterion is provided to determine the potential to reach the side crust. Separate relocation of control materials, metals, and oxides, including dissolution are considered.

In MAAP, there are two potential paths for corium to relocate from the core region into the lower plenum: sideward relocation and downward relocation. For sideward relocation, side crust around the corium pool in the core region fails. Only molten material is relocated. For downward relocation, the core support plate fails due to creep. Both molten and solid material is relocated. Hence, different relocation paths may lead to substantially different amounts of corium relocating into the lower plenum.

In ASTEC, in-vessel core degradation starts with highly exothermic zircalloy oxidation. As the core heats up, fuel rod ballooning and cladding rupture is modelled. Melting and relocation of control rod absorbers occur first. Formation of eutectic mixtures with lower melting point is considered. Fuel melting and loss of the original geometry occurs at around $2500 \mathrm{~K}$ after dissolution of UO2. In-core molten pool formation with crust is modelled. As the core heats up further due to decay heat, the crust is breached and corium relocation to the lower plenum occurs. Both sideward and downward relocations can be calculated by ASTEC code, depending on the corium melt progression. However, in both cases it is associated to the heat up and failure of the corium crust and only molten corium is relocated to the lower head. The mechanical failure of the core support plate being not simulated, the corium flows down through the holes in the plate. 
7.2.2. Discussion on the Expected Trends and Values. In this phase, the core is heating up by the decay heat. Cladding oxidation will add additional heat to the core. At some point, the fuel will start to melt and relocate within the core. When the fraction of core melted becomes sufficiently high, the core material will start to relocate to the lower plenum. Both codes are expected to track this integral behaviour with the same level of precision.

Because key phenomena such as cladding oxidation and melt progression have positive feedback, some uncertainty is expected in the accident progression in this phase. The total amount of zircalloy available for oxidation and the availability of steam provide some envelop on the total mass of hydrogen generated in the core. However, depending on the logic built in the models, the steam may flow through the damaged core and react with zircalloy or bypass the damaged core.

The melt progression in the core and relocation to the lower head also has uncertainties. First, the core geometry when it begins to melt and collapse (fuel rod collapse criteria may produce solid debris in addition to molten fuel) is subjected to uncertainties. Second, the way corium flows and solidifies in contact with colder structures is complex and is typically non-axisymmetric. Therefore, it is expected that there will be substantial uncertainty in the time and amount of initial corium relocation into the lower plenum. The total amount of hydrogen generated in the core may be somewhat more consistent but again will depend on the permeability of the damaged core to steam flow.

\subsubsection{Discussion on the Significant Discrepancies between the Codes}

(1) Core Heat-Up and Hydrogen Generation. A_REF should be compared with M_SEN for the accumulator isentropic gas expansion case and A_SEN should be compared with M_REF for the isothermal accumulator gas expansion case. For the isentropic accumulator gas expansion case, the accumulator injection ends at around 9000 seconds and the core is not quenched in both codes. Substantial fraction of the cladding has been oxidized in both codes as well. For the isothermal accumulator gas expansion case, the accumulator injection ends at around 14000 seconds and the core is quenched in both codes. Only a small fraction of the cladding has been oxidized in ASTEC. MAAP predicts a momentary temperature excursion during the accumulator injection period, which leads to a cladding oxidation spike. The momentary temperature excursion predicted by MAAP is an exception and indicates the fine boundary between the coolable and uncoolable accumulator injection rate. A rapid cladding oxidation brings the core to melting and to form a molten pool. Subsequent melt relocation within the core brings it back to a coolable geometry. Hence, the initial condition of this phase is nearly identical between the two codes.

For the isentropic accumulator gas expansion case, the core is not quenched and hence there is no change in the peak cladding temperatures after the accumulator injection ends. However, cladding oxidation, which has been stopped due to the lack of available area of cladding to react with steam, resumes as the new cladding surface becomes uncovered once the water level in the core starts to decrease. At the end, both codes predict about $510 \mathrm{~kg}$ of $\mathrm{H} 2$ generated in the core.

For the isothermal accumulator gas expansion case, the quenched core starts to heat up after the accumulator injection ends. Shortly after it starts to heat up, rapid oxidation of cladding occurs and the fuel temperature increases rapidly. Note that the rapid oxidation of cladding is delayed for MAAP because some of the cladding has already been oxidized when the temporary heat up occurred before. At the end, both codes predict about $600 \mathrm{~kg}$ of $\mathrm{H} 2$ generated in the core. Compared to the isentropic accumulator gas expansion case, more hydrogen is generated at the end because the core is less severely damaged and more zircalloy is accessible to the steam flow.

Overall, both codes predict similar results in the core heat up and hydrogen generation after the accumulator injection ends.

(2) Core Material Relocation to Lower Plenum. Figure 12 depicts the debris bed layer temperatures predicted by the two codes. Figure 13 depicts the evolution of the relocated mass to the lower plenum. A_REF should be compared with M_SEN for the accumulator isentropic gas expansion case and A_SEN should be compared with M_REF for the isothermal accumulator gas expansion case. Both codes predict similar initial core slumping time. For the isentropic accumulator expansion case, the initial core slumping occurs at around 15500 seconds in both codes. For the isothermallike accumulator expansion case, the initial core slumping occurs at around 22500 seconds in MAAP and 21000 seconds in ASTEC. However, the amount of core initially slumped is significantly different between the two codes. For the isentropic accumulator expansion case, MAAP predicts around $70000 \mathrm{~kg}$ whereas ASTEC predicts $130000 \mathrm{~kg}$. For the isothermal-like accumulator expansion case, the amount of core initially clumped is about $40000 \mathrm{~kg}$ for MAAP and $120000 \mathrm{~kg}$ for ASTEC. Hence, ASTEC predicts significantly higher initial mass of core material relocated into the lower plenum, which leads to an earlier vessel failure.

Note that significantly larger core material relocated into the lower plenum predicted by ASTEC does not lead to an equally larger RCS pressure spike as shown in Figure 14. ASTEC predicts a smaller heat transfer rate between the corium in lower plenum and the overlying water as it will be explained later.

\section{Fourth Phase: Corium Interaction with the RPV Lower Head and RPV Failure}

8.1. Phenomenology Analysis. The initial molten corium relocated into the water-filled lower plenum will produce a huge steaming and pressure spike in the vessel. The molten corium jet will break up into particulates as it falls through the water in the lower plenum. The particulates will be quenched promptly, causing rapid steaming. Because of the magnitude of the steaming, the steam generated may not completely 


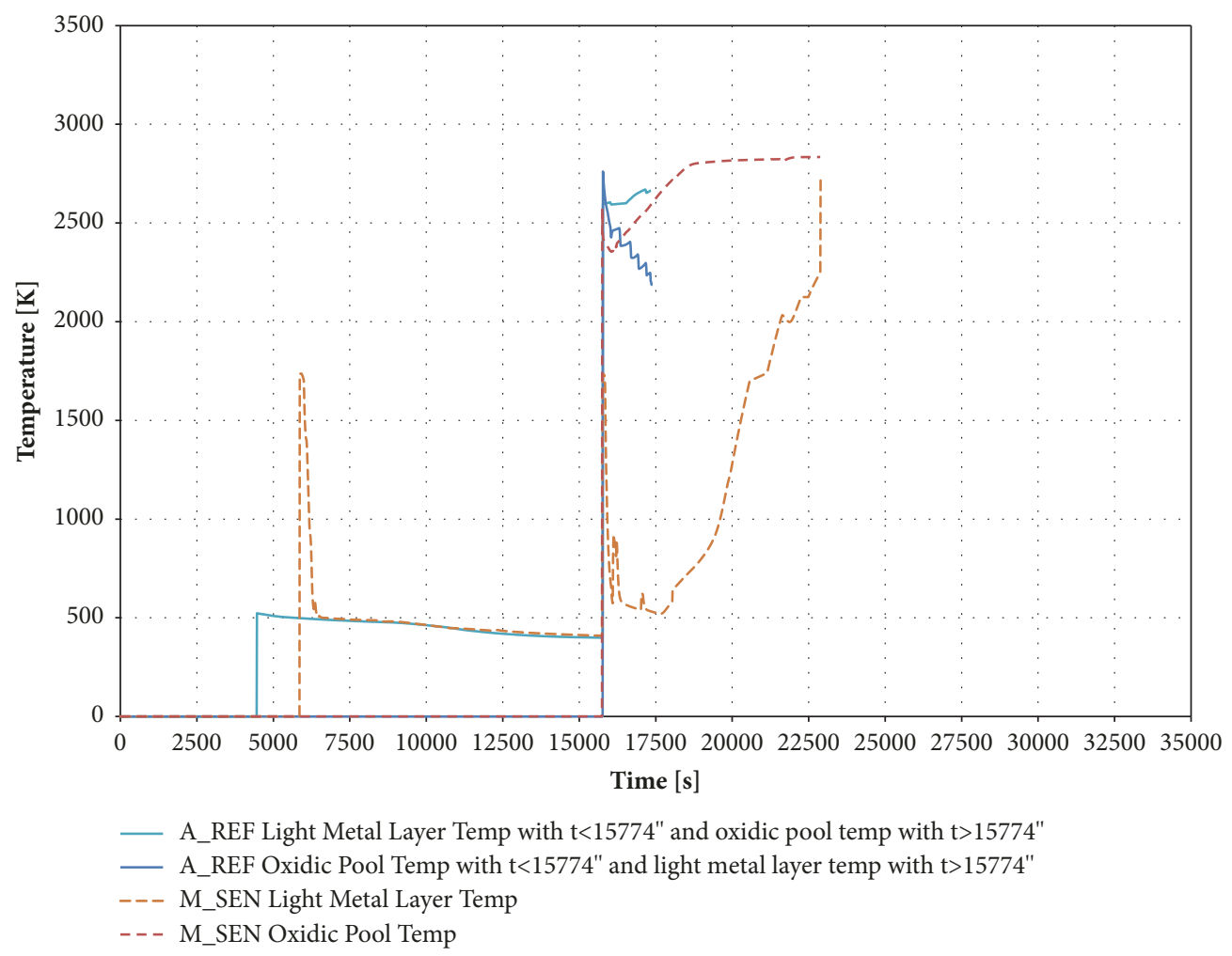

FIGURE 12: ASTEC vs MAAP lower plenum corium layer temperature comparison (the steel layer temperature reading in ASTEC begins with the onset of core degradation even though only a few milligrams are being relocated before the significant slumping occurs at 15774 seconds).

condense in the liquid pool before it is released to the gas space, causing a sudden pressure increase. Some unreacted zirconium in the particles may react with steam and produce hydrogen. Depending on the height of the water pool, the fall height, and the size of the jet, the molten jet may not break up completely. The intact jet arriving at the lower head will spread over the vessel bottom and form a contiguous layer. The quenched particles will fall on top of the contiguous layer and form a particle bed. The lighter metal and heavier oxides in the contiguous layer may separate and form a metal layer atop the oxide layer. If there is sufficient amount of unreacted zirconium present in the debris, some of the uranium oxide may be reduced into metallic uranium and, with other metals, form a heavy metal layer at the bottom. Thus, the debris bed will stratify according to the density of the material: heavy metal layer at the bottom, oxide layer in the middle, lighter metal layer at the top, and the particle bed submerged in the metal layer. Subsequent core relocations will disrupt the initial debris bed layers but they will gradually migrate towards the stratified configuration via continuous melting and freezing.

The molten corium that comes in contact with the vessel wall will freeze and form a crust. Similarly, an upper oxidic crust will form between the molten metal layer and the oxide layer because of the big difference in the melting temperatures of oxidic debris and metal. Thus the initial debris bed in the lower plenum will consist of the molten oxidic pool on the bottom surrounded by crust, a molten metal layer above the upper crust, and a particle bed partially submerged in the metal layer, with the possibility of a metallic-uranium-rich high density layer below the molten oxidic pool. There may not be a complete separation of metal at the time of corium delivery. Finally there will be an overlying water pool.

Before the lower plenum water is depleted, the debris bed will lose heat to the overlying water. The upward heat transfer rate will be limited by the counter-current flooding limitation in the particle bed. Once the overlying water has boiled off, the debris bed will start to heat up. The particle bed will melt due to its decay heat and gradually migrate to the oxidic pool. Since the decay heat in the debris bed is expected to be much larger than the heat loss to the vessel internals and to the below-vessel structures by thermal radiation, the debris bed will start to heat up.

As the debris bed heats up by the decay heat, the molten pool in the debris bed will get larger as the crust melts. A natural circulation in the pool will maintain the temperature distribution in the molten pool fairly uniform and close to the melting temperature of the oxidic pool. Hence, most of the decay heat in the early heat up phase goes into the latent heat of melting the debris or the crust and growing the molten pool. The boundary of the debris bed, the vessel wall and metal layer, are protected by the thick crust and is not affected by the debris bed heat up until the crust becomes thin.

As the molten pool grows and the crust becomes thin, the conduction heat transfer rate in the crust increases. The increasing heat flux to the vessel wall will eventually attack the 


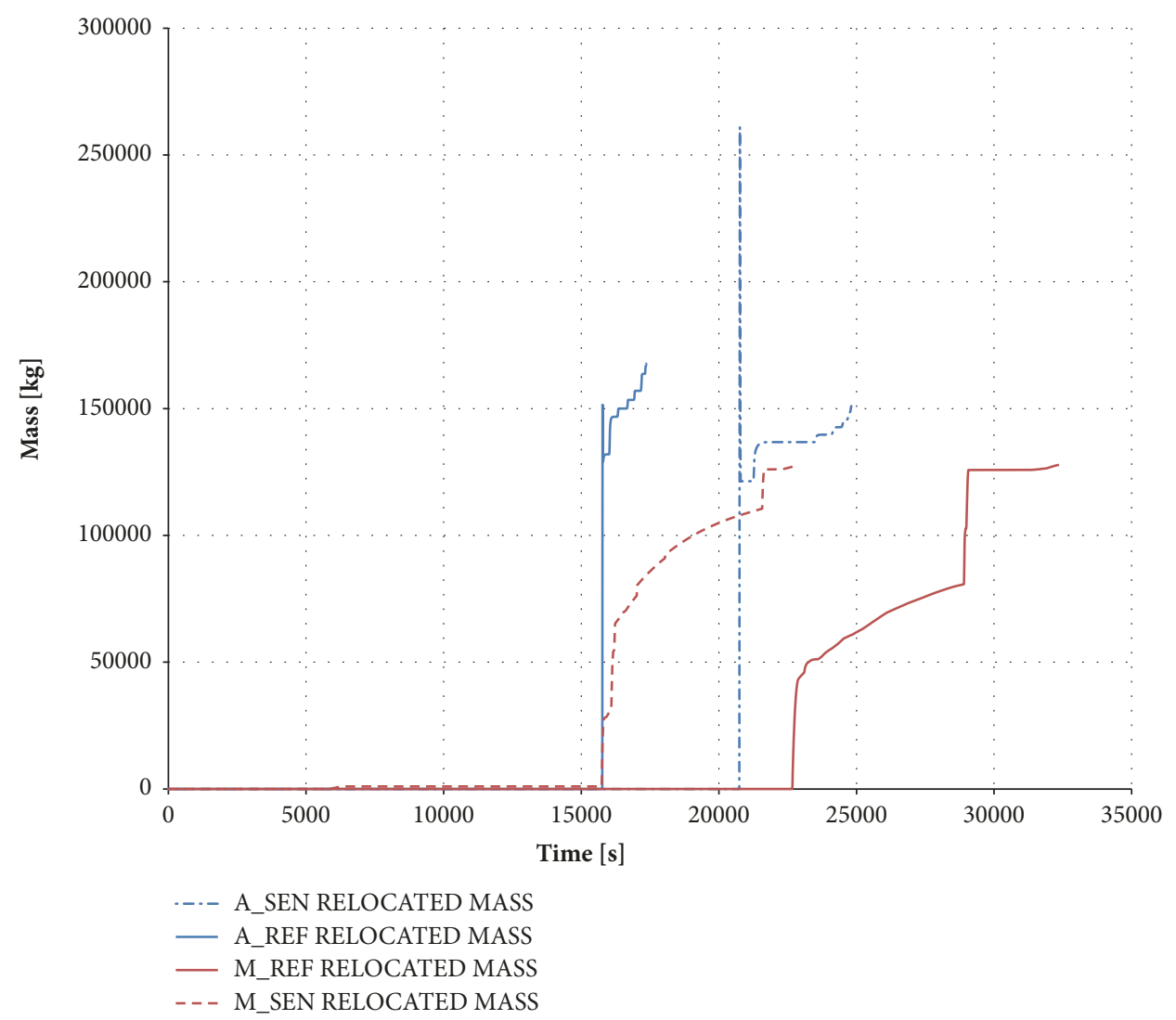

FIGURE 13: Evolution of the relocated mass to the lower plenum (at around 20760 seconds, there seems to be a spurious value of the relocated mass into the lower plenum in the ASTEC sensitivity case).

vessel wall and penetrations and fail the vessel. The natural convection heat transfer coefficient in the molten pool is lowest at the bottom and highest near the top. Therefore, the bottom crust (i.e., the crust between the vessel wall and the oxidic layer) will be thickest at the bottom and thinnest at the top, and thermal attack and vessel failure is expected to occur near the top of the debris bed.

When the vessel wall is overheated, it usually fails by material creep. If penetrations are present in the lower head the weld holding the penetration tube to the lower head can fail and push out the penetration. Both vessel failure mechanisms are preceded by lower head overheating; presence of penetrations will accelerate vessel failure somewhat.

The vessel can also fail by metal layer attacking the vessel wall. Unlike the oxidic pool, the vessel wall adjacent to the metal layer is not protected by the crust. The upward heat transfer rate in the molten oxidic pool is fixed by the decay heat generated in the pool and the split between the upward and downward heat transfer rate in the pool. The upward thermal radiation heat transfer rate in the metal layer is also somewhat fixed because the metal layer temperature cannot be too far away from the steel melting temperature; otherwise the vessel wall adjacent to the metal layer will melt. The difference between the heat received from the oxidic pool and the heat rejected by thermal radiation to vessel internals is directed to the sideward heat transfer to the vessel wall.
Hence, the sideward heat flux depends on the thickness of the metal layer; the thinner the metal layer the higher the heat flux. This phenomenon is referred to as "focusing effect". When the top metal layer is sufficiently thin the adjacent vessel wall will melt and fail.

Beside the debris bed slowly heating up and eventually attacking the vessel wall or penetrations, the vessel can also fail by late arriving molten corium attacking the vessel wall or penetrations locally before exchanging heat with the preexisting debris bed. These late arrivals will not encounter water in the lower plenum and will remain molten.

With several chemical species competing for oxygen in the molten pool, some of the uranium oxide can lose its oxygen and become metallic uranium, especially when large amount of unoxidized zirconium is present. Depending on the amount of molten steel present in the pool compared to the metallic uranium, the metal phase can become heavier than the oxidic phase and it will separate out to form a heavy metal layer. The formation of a heavy metal layer will affect the heat transfer rate to the vessel wall and hence influence vessel failure. The greatest impact of the heavy metal layer is expected in transient situations when it is first formed and when it becomes lighter than the oxides, leading to a layer inversion. During a layer inversion, the metal can become significantly overheated when it rises to the top through the oxide layer and merges with the top metal layer. Also, the 


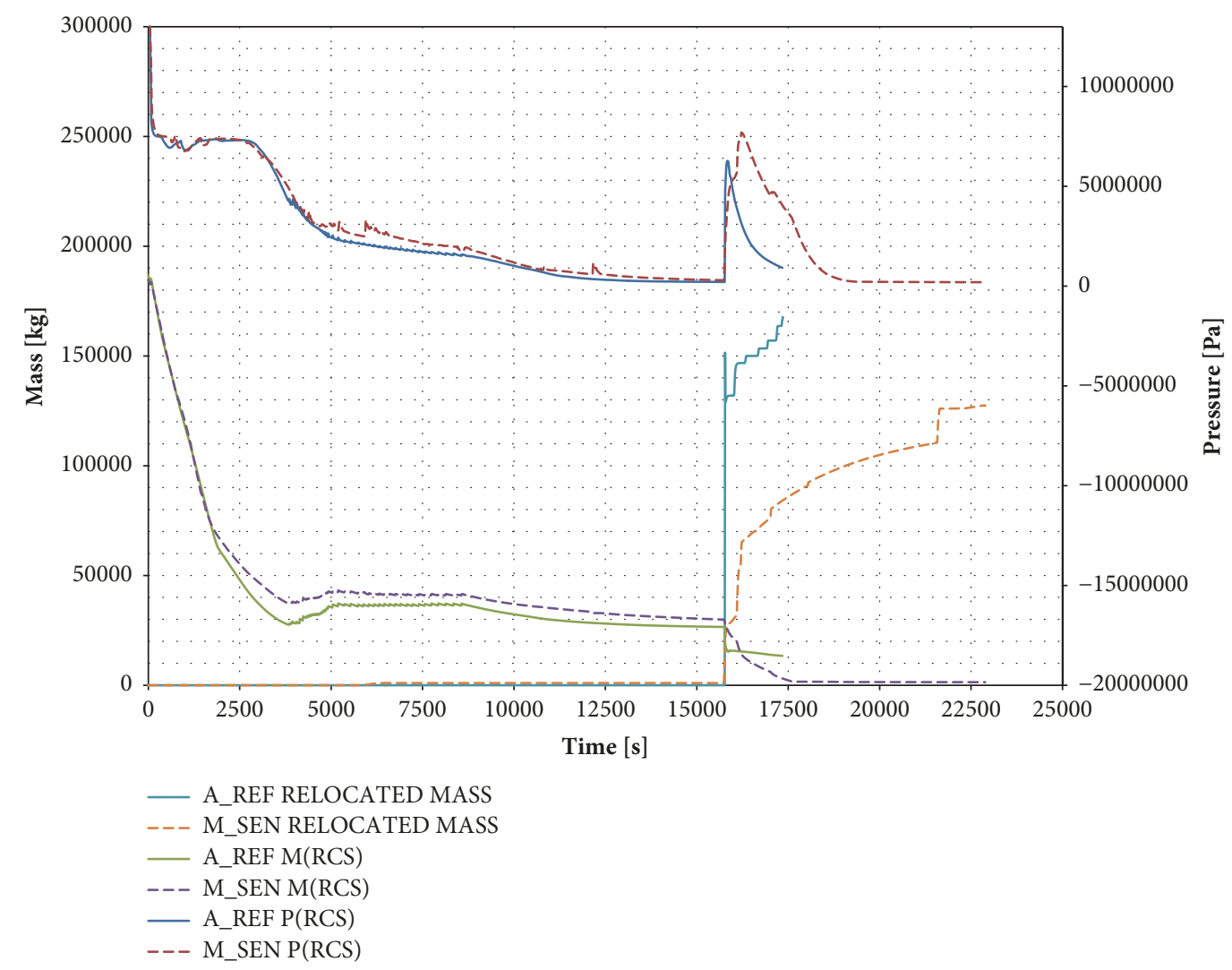

FIGURE 14: Primary pressure vs primary water mass and corium relocated mass to the lower plenum.

formation of heavy metal layer will take some material from the light metal layer, thereby reducing the light metal layer thickness and making the "focusing effect" worse.

Chemical equilibrium and phase diagram of the material present in the debris bed also affect physical properties such as specific heat, density, thermal conductivity, latent heat of melting, and melting temperature. Physical properties affect heat transfer and hence vessel failure. However, they are expected to have minor impact, within the uncertainty of the phenomena. The main factors affecting vessel failure are the time and amount of corium relocated to the lower plenum and the layer stratification affecting the top metal layer characteristics. The relocation time is important because of the decay heat; the early arriving corium will have significantly higher decay heat per unit mass. The amount of water in the lower plenum is also important.

\subsection{Conclusions on the $4^{\text {th }}$ Phase}

8.2.1. Code Capabilities. Both codes have enough capabilities to consider all the important phenomena in the lower plenum. However, the way they treat individual phenomena is somewhat different between the two codes.

In MAAP, the corium jet breaks by entrainment in the liquid pool in the lower plenum. The particle size is determined by capillary effects. Steaming rate is determined by heat transfer in the interaction zone consisted of particles, steam, and water. Particle oxidation is considered.
In ASTEC, the fragmentation is calculated based on the same kind of model of jet break-up with debris formation. The heating and vaporization of the water is also determined. However, particles oxidation is not considered. This is done based on the fact that the uncertainties are high and this oxidation is expected to remain limited. In addition, it is conservative regarding the risk of heavy metal layer formation.

(1) The current plant uses two types of control rod material: AIC and stainless steel. MAAP cannot model stainless steel control rod. It also cannot model more than one cladding type; both $\mathrm{Zr}$ and stainless steel cladding cannot be used in a single model. Both features can be handled by ASTEC.

(2) Chemical equilibrium in the debris bed in lower plenum is not considered in MAAP; the initial material composition of the relocated corium is maintained in the lower plenum. MAAP has a simple heavy metal layer model to consider the effect of metallic uranium combining with other metals and forming a heavy metal layer below the oxide layer. Reduction of uranium oxide into metallic uranium is not explicitly modelled. Instead, when a certain temperature and mass composition criteria are met in the debris bed in lower plenum, some uranium oxide in the oxide layer is combined with some fraction of the metal layer to form a heavy metal layer. In ASTEC, chemical equilibrium is considered in the debris bed in lower plenum and the material composition in the debris bed is tracked. In addition fission products are distributed in both oxide and metallic phases 
based on their chemical affinities. This leads to a fraction of decay power in the metal layer.

(3) In version V2.1.1, ASTEC models the oxidation of metal components ( $\mathrm{U}$ and $\mathrm{Zr}$ ) in the lower plenum debris bed. However, the model is not activated by default and associated kinetics is found to be much longer than the time of vessel failure.

(4) Both codes separate the relocated corium into different layers, from top to bottom, particle bed, metal layer, and oxidic pool. However, as already anticipated above, ASTEC code evaluates phase separation based on thermochemical equilibrium in the quaternary system $\mathrm{U}-\mathrm{O}-\mathrm{Zr}-\mathrm{Fe}$, whereas MAAP code simply separates steel and $\mathrm{Zr}$ in the top metal layer plus a heavy metal layer (activated through a user option, as for the current simulations) at the bottom of the corium pool which is primarily consisted of metallic constituents of U, Zr, steel, and oxygen. Neither ASTEC nor MAAP tracks the corium at a node level but at a layer level. The properties of each layer, among which composition and chemical interactions, energy, and mass, are tracked individually throughout the accident though in a different way. Each code treats the heat transfer to the lower head vessel and heat transfer distribution, namely upwards and downwards, in a different way (even if both modelling approaches rest on the use of heat transfer correlations): MAAP starts by initially imposing a 10 centimetre thickness node of solid crust attached to the lower head vessel while in ASTEC the crust is evaluated based on heat fluxes equality from the corium to the vessel, considering the crust as an additional thermal resistance. Either way, the corium composition computation across the different layers is fundamental as it greatly impacts the initial melting temperature (solidus temperature) calculation and the relative thickness of each layer.

MAAP considers RPV failure in two steps. Several vessel failure mechanisms are considered for the initial failure: creep rupture, ejection of penetration tubes when the closure weld fails, melt ingress into penetration tubes outside of the vessel, melt jet impingement of the lower head, and overlying molten metal layer attacking the vessel wall. After the initial failure, debris above the failure location is discharged, leaving behind rest of the debris inside the vessel. The location, initial radius, and growth of the failure opening are tracked. The remaining debris in the vessel continues to heat up and eventually the entire lower head fails by creep. The subsequent failure is considered catastrophic and the remaining debris in the lower plenum is dumped into the reactor cavity.

The ASTEC V2.1.1 model does not make an explicit distinction between a first localized failure and a second extended one but these are taken into account using the rupture criterion, which may be local, and the collapse criterion, which is associated to a generalized failure of the vessel. The RPV failure criteria consist of a set of userinput threshold values of temperature, molten fraction, and mechanical stress, plus more mechanistic models of plastic strain and creep. In particular, for hemispherical lower head, a specific rupture model is available based on a Norton-Bailey type creep law and the coupled damage-viscoplasticity model developed by Lemaître and Caboche. A refined submeshing of the vessel wall is considered in this mechanical model.

In MAAP, creep rupture of the lower head is modelled using the Larson-Miller parameter method [49], which gives the failure time of a metal subjected to a constant tensile load at an elevated temperature. The temperature gradient in the lower head is considered by distributing the tensile load among individual laminae (i.e., radial nodes) in the wall such that each laminae experiences the equal strain. That is, the coldest laminae will bear the most stress. The timevarying temperature and stress are considered by considering a fractional contribution to rupture at each time step. The ultimate tensile strength is considered. The partially molten wall thickness is considered.

It is also worth noting a modelling gap in the ASTEC 2.1.1 version of the code related to the failure of mechanical penetrations, whether because of losing the welding material attached to the vessel or because of the corium penetrating inside the penetration, located at the lower head of PWR reactors.

Lastly, the lack of a thermochemical model in MAAP code may lead to incorrect compositions in stratified layers, neglecting decay power in the top metal layer due to the metallic uranium in $\mathrm{Zr}$-Fe-U. Also, MAAP models the molten steel relocation up to the top metal layer at its melting temperature independently from its initial localization, which may lead to an underestimation of the top metal layer temperature.

\subsubsection{Discussion on the Expected Trends and Values. As} discussed in the previous section, there is a large uncertainty in melt progression in the core which leads to a large uncertainty in corium relocation to the lower plenum, both in timing and in quantity. Hence, the discrepancies in the debris bed behaviour in the lower plenum do not reflect exclusively the difference in modelling but are mainly the results of different initial condition. Therefore, the lower plenum debris bed response predicted by the two code, including vessel failure, should be compared in qualitative and relative terms considering the timing and quantity of corium relocated from the core predicted by each code.

\subsubsection{Discussion on the Significant Discrepancies between} the Codes. Figures 15 and 16 show the corium mass in the lower plenum predicted by ASTEC and MAAP, respectively, for the isentropic accumulator gas expansion case. ASTEC predicts about $130,000 \mathrm{~kg}$ of core slumping initially at around 16,000 seconds followed by a gradual relocation whereas MAAP predicts about $70,000 \mathrm{~kg}$ of core slumping initially at around 16,000 seconds followed by a gradual relocation. Both codes predict little or no particle bed formation. Both codes separate metal from the relocating corium at the time of corium relocation and put it in a separate metal layer. Both codes predict that there is no heavy metal layer formed in the lower plenum. MAAP predicts lower and upper crust surrounding the oxidic pool whereas in ASTEC the mass of crust is not tracked explicitly but is included in the mass of oxidic pool. 


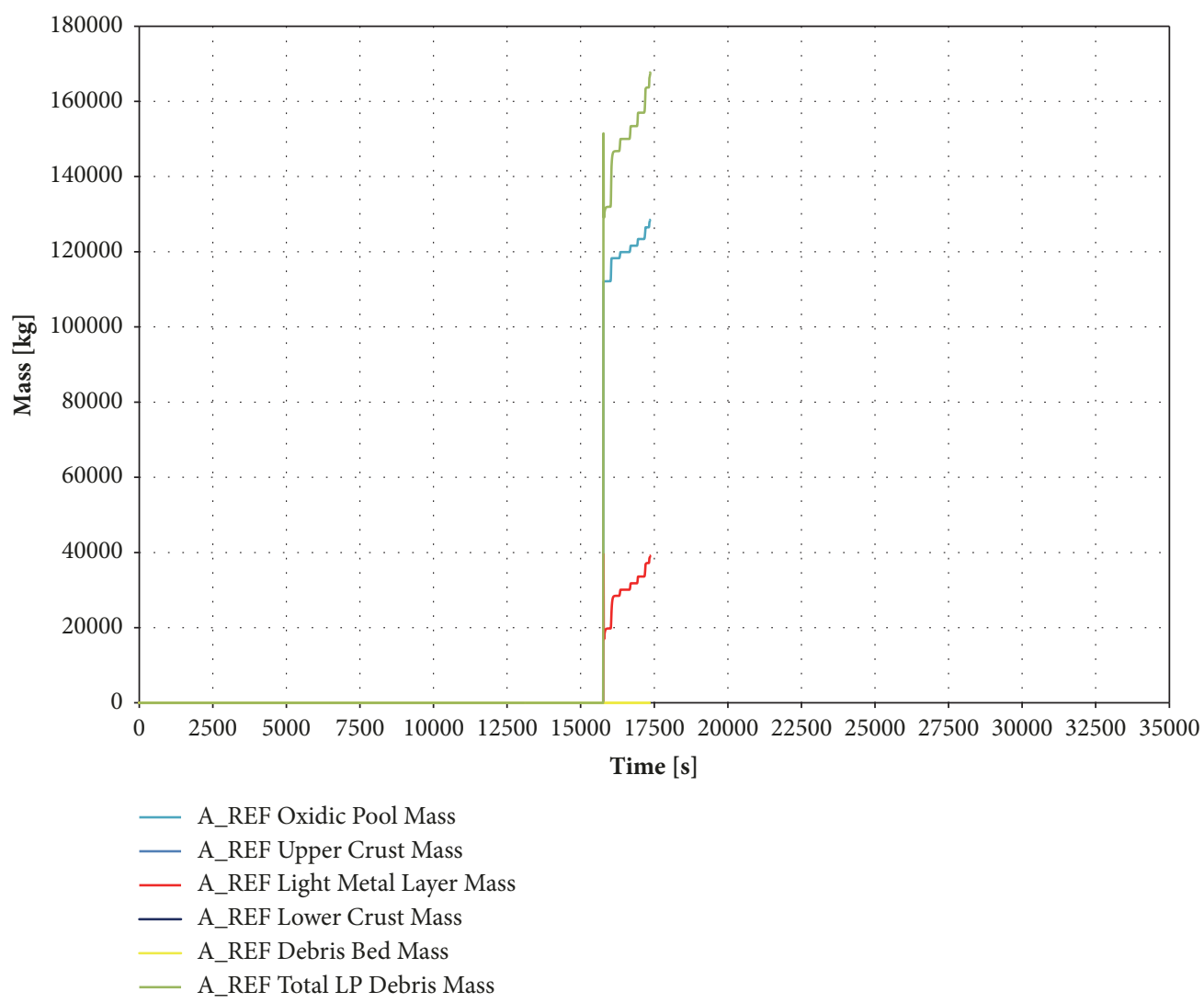

FIGURE 15: ASTEC corium stratification in the lower plenum (in this figure, the mass of the crusts is included in the mass of the oxide layer).

As shown in Figure 12, MAAP predicts the metal layer quenching by the overlying water in the lower plenum. Once the water in the lower plenum has boiled off (see Figure 14) the metal layer starts to heat up. The oxidic pool is not quenched but is cooled somewhat initially and then heats up steadily as subsequent relocation is added to the oxidic pool. ASTEC predicts gradual cooling of the metal layer by the overlying water in the lower plenum. As shown in Figure 14, ASTEC predicts that most of the water remains in the lower plenum when the vessel fails. Hence, ASTEC predicts much smaller heat transfer rate between the metal layer and the overlying water in the lower plenum compared to MAAP. The heat transfer model between the metal layer and the overlying water is improved in ASTEC V2.1.1.4.

MAAP predicts vessel failure due to creep rupture 0.55 $\mathrm{m}$ below the cylindrical portion of the vessel 7324 seconds after the initial core slumping. ASTEC predicts vessel failure due to a melt-through $0.4 \mathrm{~m}$ below the cylindrical portion of the vessel 1090 seconds after the initial core slumping. The significantly earlier vessel failure predicted by ASTEC can be explained as following:

(1) ASTEC predicts a significantly larger initial core slumping compared to MAAP. Hence the decay heat in the debris bed in lower plenum is much higher in ASTEC. Consequently the thermal load to the lower head is greater and the lower head is expected to fail earlier in ASTEC. This dominant factor affecting debris behaviour in the lower plenum is dependent on the melt progression model in the core.

(2) ASTEC predicts much smaller heat transfer rate from the top metal layer to the overlying water in the lower plenum. Consequently the corium retains most of its sensible heat such that the thermal attack to the vessel wall is greater.

(3) The debris bed model in the lower plenum, including the vessel failure mechanisms considered, affects the vessel failure time. In particular, the treatment of lower crust can be important because heat conduction through the lower crust exerts thermal load to the lower head so that the thickness of the crust can modify the temperature evolution of the lower head vessel. In MAAP, vessel failure due to creep is always preceded by the thinning of the lower crust as shown in Figure 16.

The above explanation for the discrepancy in the vessel failure time is based on the depicted results, i.e. tables and figures. Nevertheless, it is worth noting that ASTEC's prediction of a very high top metal layer temperature can be tied to the earlier vessel failure. The reasons for ASTEC to predict such a high temperature can be related to the following modelling details (these issues are discussed in more detail in [50]): 


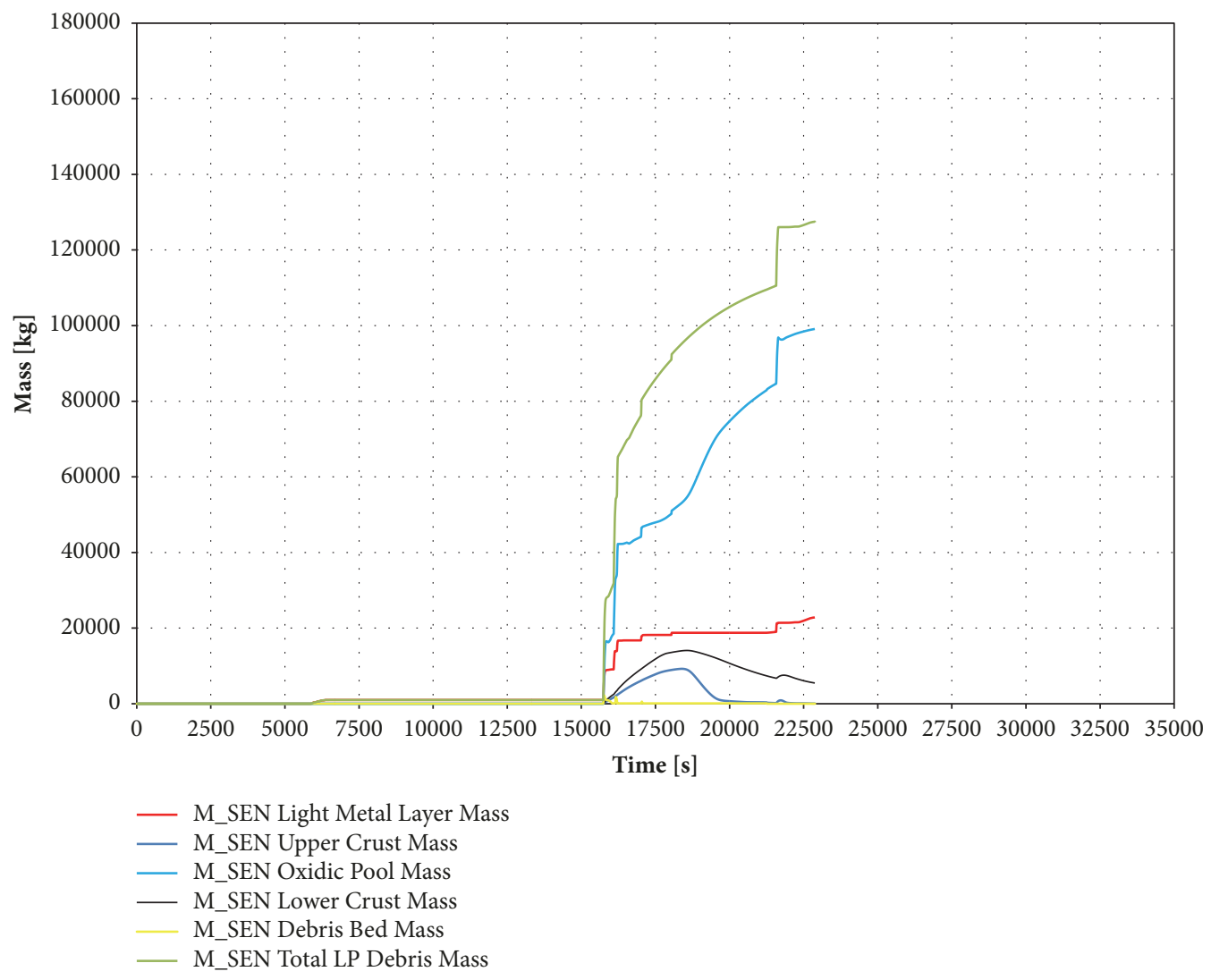

FIGURE 16: MAAP corium stratification in the lower plenum.

(1) ASTEC assumes that the molten steel relocated to the top of the corium pool has same temperature as the oxidic pool because it originates from melting of the internal structures surrounding by the oxide pool or from the ablation of the vessel wall in contact with the oxide. This leads to an overheated metal layer compared to MAAP, which accelerates ablation of the vessel wall adjacent to the metal layer. The difference in the metal layer temperature is clearly shown in Figure 12.

(2) ASTEC considers thermochemical equilibrium in the lower plenum debris bed, which leads to the presence of metallic uranium in the metal layer along with $\mathrm{Fe}$ and $\mathrm{Zr}$. This adds decay heat in the metal layer and increases heat flux to the vessel wall.

As a conclusion, the response of the debris bed in lower plenum is primarily determined by the initial delivery of corium from the core: ASTEC predicts a significantly larger initial core slumping, which leads to earlier vessel failure. In addition, ASTEC's modelling capabilities predict an overheated metal layer, which causes earlier vessel failure. Both codes predict vessel failure at the highest elevation in the molten pool. Both codes predict vessel failure shortly after the average temperature of the oxidic layer exceeds the liquidus temperature.

\section{Summary and Conclusions}

A code comparison has been performed between ASTEC and MAAP. The selected scenario is a 2 inch cold leg SBLOCA in a $900 \mathrm{MWe}$ PWR. All safety injections except the accumulators were assumed to be unavailable. Two sensitivity cases were added so that comparisons were able to be made with the same boundary conditions (i.e., the accumulator gas expansion model). The accident evolution predicted by the two codes up to the time of RPV failure was compared. The goal of this study is to identify key differences in the results and to explain the differences in terms of model differences and code user choices. The following conclusions can be derived from this study:

(1) When the same accumulator gas expansion model is used, the two codes predict similar thermal-hydraulic response until core melting and relocation. They include break flow, steaming in the core, RCS depressurization, core uncovery, natural circulation and heat transfer between the vessel and SG, core heat up, cladding oxidation, and hydrogen generation. Even the intricate feedback between the RCS pressure and the accumulator injection predicted by the two codes is consistent.

(2) The code comparison exercise highlights the importance of the user choice on model parameters. Once 
the same accumulator gas expansion model was selected, the overall results look similar and minor differences are explainable.

(3) Both codes predict that the core has already uncovered and is heating up with cladding oxidation when the accumulator injection begins. Moreover, both codes predict that the injection may or may not quench the core. With isothermal gas expansion, the accumulator injection rate is a little higher at the beginning and both codes predict core quenching. With isentropic gas expansion, the accumulator injection rate is a little lower at the beginning and both codes predict the core is not quenched.

(4) Both codes are capable of predicting the formation of a molten pool in the core which cannot be cooled by a late injection of coolant.

(5) The major difference between the two predictions is found in the melt progression and core relocation to the lower plenum. ASTEC predicts a significantly larger core relocation mass to the lower plenum compared to MAAP during the first instants. On the other hand, the timing of core relocation is similar, about 7,000 seconds after the accumulator trip off.

(6) The two codes predict similar but somewhat different debris bed behaviour in the lower plenum. ASTEC predicts much lower heat transfer rate between the top metal layer and the remaining water in the lower plenum. Consequently the upper metal layer temperature decreases at a slower rate and the oxidic pool remains hot until vessel failure. There is still water in the lower plenum when the vessel fails. On the other hand, MAAP predicts the top metal layer and the oxidic pool to cool down faster. Once the water in the lower plenum has boiled off, the metal layer and oxidic pool start to heat up until the vessel fails. ASTEC assumes that the molten steel relocated to the metal layer is in thermal equilibrium with the oxidic layer. It also considers chemical equilibrium in the debris bed, predicting presence of metallic uranium in the metal layer and associated decay heat. Hence it predicts higher metal layer temperature compared to MAAP. Nevertheless, keeping in mind such differences in the lower plenum debris bed modelling, their impact on the vessel failure time is not discernible in this study. Therefore, the earlier vessel failure time predicted by ASTEC should be mostly assigned to the larger core relocation.

\section{Nomenclature}

Accum: Accumulator

AFW: Auxiliary feedwater system

AIC: Silver Indium Cadmium

CET: Core exit thermocouples (temperature)

d: $\quad$ Derivative

DiD: Defence in depth

ECCS: Emergency core cooling system $\begin{array}{ll}\text { EFW: } & \text { Emergency Feedwater } \\ \text { FCI: } & \text { Fuel coolant interaction } \\ \text { HPSI: } & \text { High pressure safety injection } \\ \text { IVMR: } & \text { In-vessel melt retention } \\ \text { LPSI: } & \text { Low pressure safety injection } \\ \text { m: } & \text { Meter } \\ \dot{m}: & \text { Mass flowrate }\end{array}$

MBLOCA: Medium break loss of coolant accident

MCCI: Molten corium concrete interaction

MFW: Main feedwater system

MWe: $\quad$ Electric megawatt

P: $\quad$ Pressure

PCT: $\quad$ Peak clad temperature

PWR: $\quad$ Pressurized water reactor

RCP: $\quad$ Reactor coolant pump

RCS: $\quad$ Reactor coolant system

SBLOCA: Small break loss of coolant accident

SG: $\quad$ Steam generator

SI: $\quad$ Safety injection

TAF: Top of active fuel

V: $\quad$ Volume

Greek

$\gamma$ : Polytropic coefficient

$\rho$ : Density

Subscript

1: Initial condition

2: Final condition

1: Liquid

S: Isentropic expansion

$\mathrm{T}$ : Isothermal expansion.

\section{Data Availability}

The data used to support the findings of this study are available from the corresponding author upon request.

\section{Conflicts of Interest}

The authors declare that there are no conflicts of interest regarding the publication of this paper.

\section{References}

[1] G. Espinosa-Paredes, L. Batet, A. Nuñez-Carrera, and J. Sugimoto, "Severe Accident analysis in nuclear power plants," Science and Technology of Nuclear Installations, vol. 2012, Article ID 430471, 2 pages, 2012.

[2] A. Bentaïb, H. Bonneville, G. Cénérino et al., Nuclear Power Reactor Core Melt Accidents, Current State of Knowledge, D. Jacquemain, Ed., IRSN, EDP Sciences, France, 2015.

[3] M. Pescarini, F. Mascari, D. Mostacci, F. De Rosa, C. Lombardo, and F. Giannetti, "Analysis of unmitigated large break loss of coolant accidents using MELCOR code," Journal of Physics: Conference Series, vol. 923, Article ID 012009, 2017. 
[4] P. Chatelard, S. Belon, L. Bosland et al., "Main modelling features of the ASTEC V2.1 major version," Annals of Nuclear Energy, vol. 93, pp. 83-93, 2016.

[5] Fauske \& Associates, “Transmittal Document for MAAP5 Code Revision MAAP 5.02,” LLC, FAI/13-0801, 2013.

[6] MELCOR Computer Code Manuals, "Vol. 1: Primer and Users' Guide, SAND 2015-6691 R; Vol. 2: Reference Manual, SAND 2015-6692 R; Vol. 3: MELCOR Assessment Problems, SAND 2015-6693 R," Sandia National Laboratories, USA, 2015.

[7] J. P. Van Dorsselaere, M. Barrachin, S. Power et al., "The Summary of ETSON strategic orientations on research activities," ETSON Research Group Activity, vol. 63, no. 1, 2018.

[8] Source term uncertainty, recent development in understanding fission product behaviour, NEA/CSNI/R(92)2.

[9] SOAR on Containment Thermalhydraulics and Hydrogen Distribution, NEA/CSNI/R(1999)16.

[10] In-Vessel Core Degradation Code Validation Matrix, Update 1996-1999, NEA/CSNI/R(2000)21, France, 2001.

[11] State-Of-The-Art Report On Nuclear Aerosols, NEA/CSNI/ $\mathrm{R}(2009) 5$.

[12] Containment code validation matrix, NEA/CSNI/R(2014)3.

[13] F. Mascari, H. Nakamura, K. Ummlnger, F. De Rosa, and F. D'Auria, "Scaling issues for the experimental characterization of reactor coolant system in integral test facilities and role of system code as extrapolation tool," in Proceedings of the International Topical Meeting on Nuclear Reactor Thermal Hydraulics 2015, NURETH, September 2015.

[14] J. P. Van Dorsselaere, J. Mustoe, S. Power, M. Adorni, A. Schaffrath, and A. Nieminen, "ETSON views on R\&D priorities for implementation of the 2014 Euratom Directive on safety of nuclear installations," Kerntechnik, vol. 81, no. 5, pp. 527-534, 2016.

[15] W. Klein-Heßling, M. Sonnenkalb, D. Jacquemain et al., "Conclusions on severe accident research priorities," Annals of Nuclear Energy, vol. 74, pp. 4-11, 2014.

[16] J.-P. Van Dorsselaere, A. Auvinen, D. Beraha et al., "Recent severe accident research synthesis of the major outcomes from the SARNET network," Nuclear Engineering and Design, vol. 291, pp. 19-34, 2015.

[17] H. Nowack, P. Chatelard, L. Chailan, S. Hermsmeyer, V. Sanchez, and L. Herranz, CESAM - Code for European Severe Accident Management, EURATOM project on ASTEC improvement, ERMSAR, Warsaw, Poland, 2017.

[18] HORIZON2020, "In-Vessel Melt Retention Severe Accident Management Strategy for Existing and Future NPPs," https:// cordis.europa.eu/project/rcn/196923_es.html.

[19] C. Journeau et al., "SAFEST Roadmap for Corium Experimental Research in Europe," in Proceedings of the 24th International Conference on Nuclear Engineering, ICONE-24, June 2016.

[20] Organization for the Economic Co-Operation and Development (OECD) on Benchmark Study of the Accident at the Fukushima Daiichi Nuclear Power Plant (BSAF Project), Phase I Summary Report. NEA/CSNI/R(2015)18.

[21] Organization for the Economic Co-Operation and Development (OECD), Nuclear Energy Agency (NEA), Committee of Nuclear Safety Installations (CSNI), "Informing Severe Accident Management Guidance and Actions through Analytical Simulation," Report on the WGAMA Working Group, 2017 (ongoing as of June 2018).

[22] Organization for the Economic Co-Operation and Development (OECD) on State-of-the-Art Report on Molten Corium
Concrete Interaction and Ex-Vessel Molten Core Coolability, NEA/CSNI/R(2016)15.

[23] International Atomic Energy Agency (IAEA) Technical Meeting on the Status and Evaluation of Severe Accident Simulation Codes for Water Cooled Reactors, October 2017, https://www.iaea.org/NuclearPower/Meetings/2017/2017-1009-10-12-NPTDS.html.

[24] Electric Power Research Institute, "Modular Accident Analysis Program (MAAP) MELCOR Crosswalk, Phase 1 - Study," EPRI Report, 2014.

[25] S. Belon, C. Bouillet, H. Bonneville, N. Andrews, and C. Faucett, "Insight of Core Degradation Simulation in Integral Codes Throughout ASTEC/MELCOR Crosswalk Comparisons and ASTEC Sensitivity Studies," in Proceedings of the ERMSAR 2017, Warsaw, Poland, 2017.

[26] M. D’Onorio, F. Giannetti, F. Mascari, and G. Caruso, "Uncertainty analyses using the RAVEN software tool coupled with MELCOR severe accident code," in Proceedings of the ANS Best Estimate Plus Uncertainty International Conference (BEPU 2018), Lucca, Italy, 2018.

[27] Approaches and Tools for Severe Accident Analysis for Nuclear Power Plants, IAEA Safety Reports Series No. 56, IAEA, Vienna, 2008.

[28] NEA/CSNI/R(98)22: Good Practices for User Effect Reduction, Status Report, November 1998.

[29] S. N. Aksan et al., "User effects on the thermal-hydraulic transient system code calculations," Journal of Nuclear Engineering and Design, vol. 145, 1993.

[30] L. Soffer et al., "Accident source terms for light-water nuclear power plants," US Nuclear Regulatory Commission, NUREG1465, Feb 1995.

[31] F. Mascari, J. C. De La Rosa Blul, M. Sangiorgi, and G. Bandini, "Analyses of an Unmitigated Station Blackout Transient With ASTEC, MAAP AND MELCOR Code," in Proceedings of the 9th Meeting of the European MELCOR User Group, Madrid, Spain, 2017.

[32] L. Foucher, ASTEC V2.1.0.3, PWR900-LIKE Input Deck Part 1: Description of the Geometry and Initial Conditions, Rapport no. PSN-RES/SAG/2015-402, 2015.

[33] L. Foucher, ASTEC V2.1.0.3, PWR900-LIKE Input deck Part 2: Steady State Calculation, Rapport no. PSN-RES/SAG/2015-403, 2015.

[34] N. Aksan, "International Standard Problems and Small Break Loss-of-Coolant Accident (SBLOCA)," in Proceedings of the Thicket 2008, Session V, Paper 13, 2008.

[35] A. Rubio, S. Gallardo, and G. Verdú, "Sensitivity Analyses in a SBLOCA: Effect of Break Size in a HPI-Failure Scenario," in Proceedings of the International Conference on Mathematics and Computational Methods Applied to Nuclear Science and Engineering (MઐC 2011), May 2011.

[36] C. Queral, J. González-Cadelo, G. Jimenez, and E. Villalba, "Accident management actions in an upper-head small-break loss-of-coolant accident injection failed," Nuclear Technology, vol. 175, no. 3, pp. 572-593, 2011.

[37] F. D’Auria and G. M. Galassi, "Scaling in nuclear reactor system thermal-hydraulics," Nuclear Engineering and Design, vol. 240, no. 10, pp. 3267-3293, 2010.

[38] CSNI Integral Test Facility Validation Matrix for the Assessment of Thermal-Hydraulic Codes for LWR LOCA and Transients, NEA/CSNI/R(96)17, France, 1996. 
[39] Separate Effects Test Matrix for Thermal-Hydraulic Code Validation, NEA/CSNI/R(93)14.

[40] Evaluation of the Separate Effects Tests (SET) Validation Matrix, NEA/CSNI/R(96)16.

[41] US NRC NUREG-1953, "Confirmatory Thermal-Hydraulic Analysis to Support Specific Success Criteria in the Standardized Plant Analysis Risk Models-Surry and Peach Bottom”.

[42] M. Salehi and M. Shayesteh, "The accumulator effects on invessel severe accident progression of a three loop PWR nuclear power plant in a SBLOCA without safety injection system," Annals of Nuclear Energy, vol. 107, pp. 1-16, 2017.

[43] R.-J. Park, K.-S. Ha, H.-Y. Kim, and J.-H. Song, "Detailed evaluation of safety injection tank effects on in-vessel severe accident progression in a small break LOCA without safety injection," Annals of Nuclear Energy, vol. 58, pp. 54-59, 2013.

[44] International Atomic Energy Agency, Defence in Depth in Nuclear Safety, INSAG-10, International Nuclear Safety Advisory Group, 1996.

[45] F. Mascari, M. Donorio, F. Giannetti, G. Caruso, and A. Naviglio, "Analyses of unmitigated transients: small break LOCA in PWR, loss of feedwater in PWR and SBO in BWR," ADPFISSLP1-103, 2017.

[46] F. D’Auria, Ed., Thermal-Hydraulics of Water Cooled Nuclear Reactors, Woodhead Publishing, Duxford, UK, 2017.

[47] L. Li, Y. Zhang, W. Tian, G. Su, and S. Qiu, "MAAP5 simulation of the PWR severe accident induced by pressurizer safety valve stuck-open accident," Progress in Nuclear Energy, vol. 77, pp. 141151, 2014.

[48] J. N. Reyes Jr, "Passive Safety System Design \& Certification Testing in APEX and NuScale. Joint ICTP-IAEA Course on Natural Circulation Phenomena and Passive Safety Systems in Advanced Water Cooled Reactors," The Abdus Salam International Centre for Theoretical Physics, May 2010.

[49] F. R. Larson and J. Miller, "A Time-Temperature Relationship for Rupture and Creep Stresses," Trans. ASME, pp. 765-775, 1952.

[50] L. Carénini, F. Fichot, and N. Seignour, "Modelling issues related to molten pool behaviour in case of In-Vessel Retention strategy," Annals of Nuclear Energy, vol. 118, pp. 363-374, 2018. 

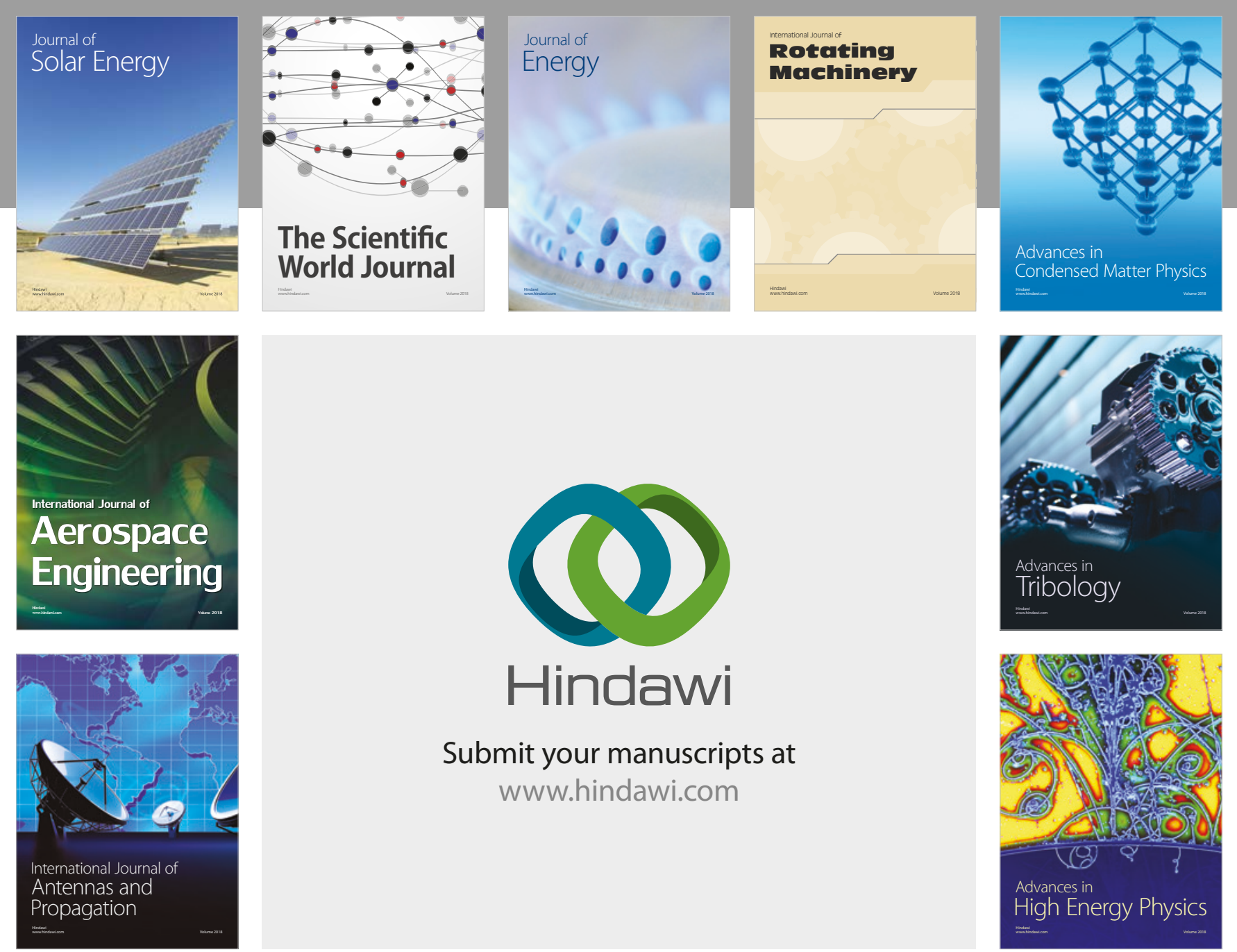

Submit your manuscripts at

www.hindawi.com
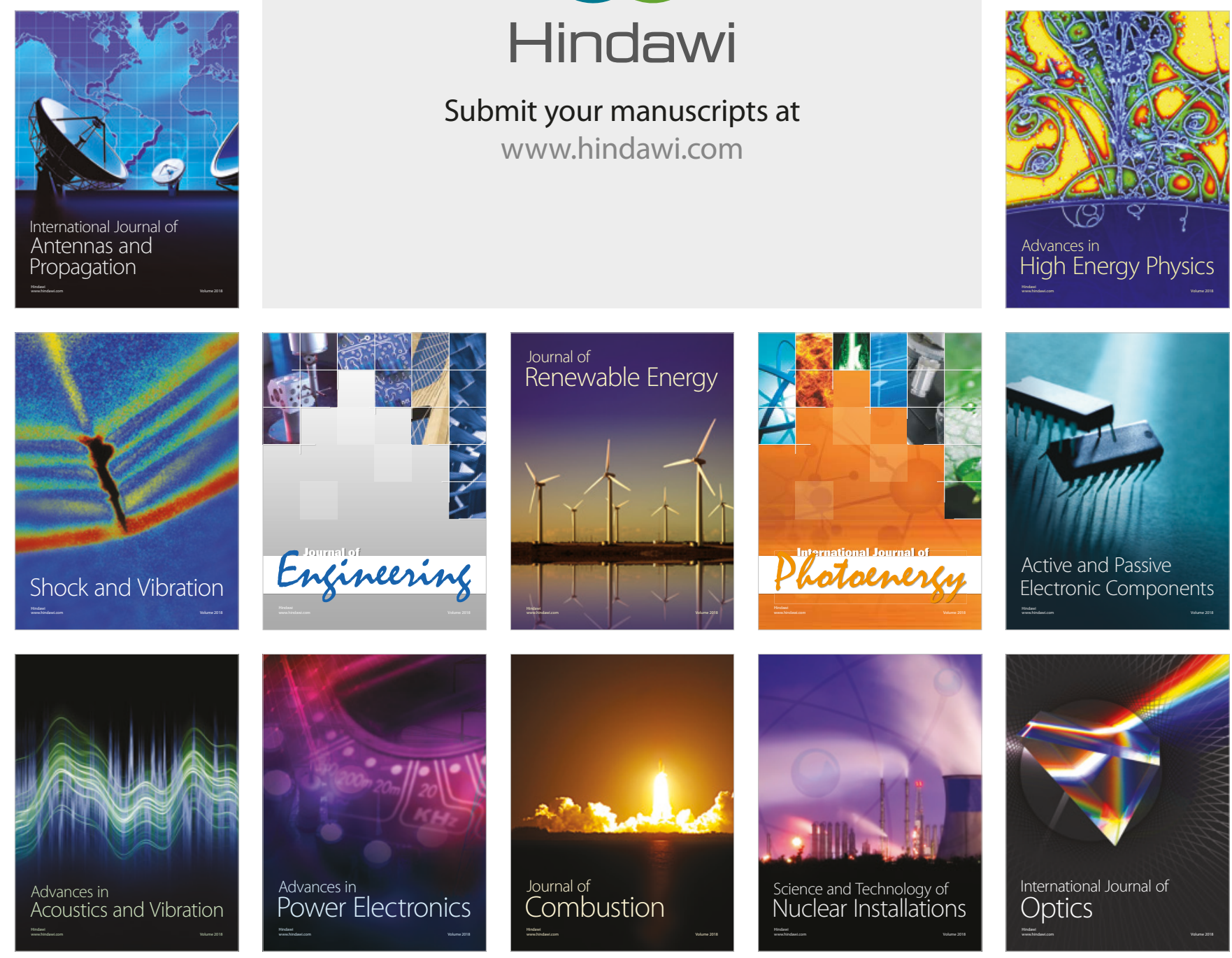